\title{
EL MUSEO DE BELLAS ARTES DE CÓRDOBA Y SU APERTURA A LA CONTEMPORANEIDAD DESDE 1904
}

\author{
ALBA OSA PARRA \\ Universidad de Córdoba
}

\section{Resumen}

La dirección de Enrique Romero de Torres en el museo de Bellas Artes de Córdoba supuso un intento de adaptación a los nuevos tiempos, al igual que se trataba de hacer en otros museos de bellas artes españoles. En Córdoba se contempló una renovación del museo a partir de ciertas mejoras museográficas y el incremento de fondos con obras pertenecientes a las nuevas corrientes artísticas, lo que permitió la creación de la Sección de Arte Moderno a principios del siglo XX. Posteriormente, la institución sufrió un estancamiento que se prolongaría hasta inicios de la década de los ochenta, cuando Fuensanta García de la Torre asumió la dirección de museo, realizando una valiosa labor en cuanto a la ampliación de fondos ligados al arte contemporáneo sobre artistas coetáneos locales y cercanos al entorno cordobés.

\section{Palabras clave}

Museo de Bellas Artes, Córdoba, arte contemporáneo, incremento de fondos.

\section{CÓRDOBA'S MUSEO OF BELLAS ARTES AND ITS OPENING TO CONTEMPORARY TIMES SINCE 1904 \\ Abstract}

At a time when art galleries in Spain were adapting to new times, Enrique Romero de Torres was a turning point with regard to the modernisation of the Museo de Bellas Artes of Córdoba .In Córdoba, such renovation included both improvements of the museum as well as the increase of the collection with the acquisition of works from the newest artistic trends, which allowed the creation of the Section of Modern Art in the early $20^{\text {th }}$ century. Afterwards the museum reached an impasse that was resolved in 1981 with the appointment of new director, Fuensanta García de la Torre. She carried out valuable work regarding the expansion and acquisition of contemporary art pieces. Moreover, she organised exhibitions, workshops and activities involving both local artists and those with a close relation to the city of Córdoba.

\section{Keywords}

Córdoba's art gallery, art collection expansion, modern art, contemporary art.

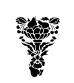




\section{Introducción}

El Museo de Bellas Artes de Córdoba ha sufrido una importante transformación desde su creación hasta la actualidad, tanto en sus colecciones como en sus funciones, respondiendo a las nuevas necesidades sociales y a la mayor demanda cultural. En el momento en que Enrique Romero de Torres comenzó su trabajo en el museo provincial, buscó adaptar la institución a los nuevos tiempos adquiriendo y aceptando donaciones de obras de artistas coetáneos para la colección. El conjunto de estas obras dio lugar a la creación de la "Sección de Arte Moderno" en 1902. Los numerosos contactos de Enrique Romero con otros artistas, sobre todo en la capital, favoreció la ampliación de los fondos con obras de reciente creación, consiguiéndose estas piezas tanto por adquisición, como por donación de los propios artistas. Tras la jubilación de Enrique Romero, su sobrino, Rafael Romero de Torres Pellicer, asumió el cargo como director, iniciándose un periodo de decadencia del museo que llevó por diversos motivos hasta su cierre.

Posteriormente en la década de los ochenta y con la llegada de Fuensanta García de la Torre como directora del Museo de Bellas Artes de Córdoba, se dotó al museo de las instalaciones y condiciones necesarias para retomar su funcionamiento como institución cultural. Se continuó la labor de ampliar una colección que definiera al museo y le otorgara prestigio, por lo que se estableció un criterio de adquisición que priorizaba obras de artistas que estuvieran en relación con la provincia cordobesa. Una ardua tarea que conjugó con otras labores como la remodelación de varias áreas de sus áreas, dotar al edificio de las necesidades básicas como agua corriente y luz, además de la creación de almacenes y un taller de restauración, amén de la implantación de un sistema de seguridad. La transformación que sufrió el museo tuvo el objetivo de crear una institución que formara parte la sociedad, concepto ligado a las nuevas teorías museológicas y museográficas que buscan establecer la educación y la difusión del patrimonio como una de las principales funciones del museo. A partir del 2013 la institución ha seguido incrementando sus fondos de arte contemporáneo a través de la recepción de numerosas donaciones y depósitos de diversa índole, siguiendo el criterio de colección, ya marcado anteriormente desde 1992, donde las piezas recibidas deben de formar parte del panorama artístico cordobés.

El estudio de las colecciones del Museo de Bellas Artes de Córdoba permite valorar y difundir una parte del patrimonio cultural actual que se gesta en la ciudad. Además de conocer la identidad de la institución museística, que está marcada por las piezas que alberga, constituyendo la colección como la parte esencial de la gestión del museo. La preocupación por parte del museo de adquirir nuevas obras comenzó con la finalidad de completar vacíos dentro de la colección y poder ofrecer al espectador una evolución del arte andaluz, y sobre todo local, del siglo XX, además de generar en el público una sensibilidad hacía el arte actual.

\section{Colección e incremento de fondos en los museos de Andalucía}

El ingreso de un bien cultural del patrimonio cultural en una institución museística supone su interpretación, documentación e investigación, además de su protección y preservación garantizadas a través de la legislación ${ }^{1}$. En la creación de un museo, y en su consiguiente desarrollo, es primordial atender a la política de colecciones, siendo esta la columna vertebral que marca las directrices y parámetros de la gestión de la institución museística y favorece el cumplimiento de sus funciones y objetivos que deben estar completamente definidos ${ }^{2}$. El museo tiene el cometido de establecer una serie de criterios científicos y técnicos para la formación de su colección, unos criterios que correspondan a su historia, cultura y tradición, de modo que el museo colecciona aquellas piezas que sean significativas y representativas de las manifestaciones culturales humanas, además de poseer un valor didáctico y/o estético ${ }^{3}$. Crear una colección representativa y que otorgue prestigio

\footnotetext{
${ }^{1}$ LEWIS, 2006:1

2"Museos, Colecciones". En: <https://www.mecd.gob.es/cultura-mecd/areascultura/museos/colecciones/introduccion.html>. [Consultado 25/06/2017].

3 ALQUÉZAR YÁÑEZ, 2008: 81-83.
} 
a la institución no es fácil, por lo que es crucial un buen funcionamiento en la gestión del museo, contando con suficientes recursos económicos y administrativos, además de una serie de profesionales competentes que lleven a cabo esta misión. Las funciones decimonónicas del museo - coleccionar, conservar y exhibir - han ido desarrollándose hacía la investigación y la educación en función de la demanda cultural, generando instituciones operativas que buscan la estimulación de la sociedad. El museo como organismo tiene la obligación de documentar, conservar, investigar y difundir sus fondos, haciendo de éstos una propuesta cultural educativa y beneficiosa socialmente ${ }^{4}$. En este sentido la adquisición de fondos se convierte en una de las labores destacadas, y más delicadas, a desarrollar por el museo. A pesar de ello, en un primer momento, la adquisición no se contemplaba dentro del concepto de museo siendo así que en 1947 el ICOM establecía su definición como: toda institución permanente, que conserva y expone colecciones de objetos de carácter cultural o cientifico, para fines de estudio, de educación y de deleite. Sin embargo, posteriormente, en 1974 el Comité Internacional de Museos incorporó la obligación de adquirir a la definición, llegando hasta la actualidad en que el ICOM establece el museo como: una institución permanente, sin fines de lucro, al servicio de la sociedad y abierta al público, que adquiere, conserva, estudia, expone y difunde el patrimonio material e inmaterial de la bumanidad y su ambiente con fines de estudio, educación y recreo, definido en la $22^{\circ}$ Asamblea General en Viena, celebrada el 24 de agosto de $2007^{5}$.

A partir de las normas mínimas que establece el Código de Deontología del ICOM, las cuales pretenden garantizar y ejecutar los servicios del museo, se puntualiza que el museo tiene la misión de adquirir, preservar y difundir sus colecciones ${ }^{6}$.El museo selecciona las piezas considerando los criterios y metodologías específicas a las que estén dirigidas, si bien para desarrollar esta labor de incremento, el museo debe seguir las directrices marcadas por los documentos deontológicos y jurídicos a nivel territorial, nacional e internacional. Los bienes que van a adquirir deben tener un interés para el museo y contribuir a cumplir la misión de educar a la sociedad ${ }^{7}$. Así, en la política de colecciones del museo se parte de una planificación razonada, buscando crear un discurso coherente con las piezas de la colección y evitando caer en un juicio o gusto personal. Existen diversas formas en cuanto al ingreso de un objeto en la institución, siendo las más habituales: recolección, permuta, compra, donación y depósito. Cualquiera de ellas supone un complicado proceso administrativo y legal ${ }^{8}$.

Atendiendo a los museos de bellas artes se constata una cierta ambigüedad en torno a su propia denominación, pues en su colección podrían acoger cualquier tipo de objeto artístico y de cualquier época, pero, sin embargo, en la mayoría de museos de esta índole se limita su alcance cronológico para permitir a la institución una mejor organización y exhibición de sus fondos?.

En el Real Decreto del 20 de marzo de 1967 se incentiva la creación de museos provinciales en las ciudades que contasen con un gran patrimonio. Los fondos de estos museos surgen de las desamortizaciones acaecidas en 1835 y 1868, con la finalidad de proteger el patrimonio que anteriormente estaba en manos de las instituciones religiosas y pasaría a ser custodiado por el Estado. Además, conservarán los objetos arqueológicos de sus respectivas provincias ${ }^{10}$. A pesar del Decreto del 24 de julio de 1913 del rey Alfonso XII, que declara la fundación de los museos provinciales de bellas artes, muchos ya habían sido creados y tutelados por las comisiones de monumentos o las Academias de Bellas Artes.

Atendiendo a los fondos de las instituciones museísticas de Andalucía, en ocasiones se incrementan con depósitos de otros museos y de diversos organismos como las

${ }^{4}$ MARTÍN MARTÍN, 1994: 271-273.

5 “Definición del Museo - ICOM". En: $<$ http://icom.museum/la-vision/definicion-del-museo/L/1/> [Fecha de acceso: 28/07/2017].

${ }^{6}$ LEWIS, 2006:7.

${ }^{7}$ LADKIN, 2006: 17-20.

8 PENUUELAS I REIXACH, 2008: 280-285.

9 ALONSO FERNÁNDEZ, 1993:142-145.

${ }^{10}$ HERNÁNDEZ HERNÁNDEZ, 1994: 35. 
diputaciones provinciales y la Consejería de Cultura, además de las donaciones particulares e incluso procedentes de los propios artistas. Sin embargo, la mayoría de Museos de Bellas Artes tienen a lo largo de su historia una serie de limitaciones económicas y un continuo cambio en relación a su administración -siendo en la actualidad de titularidad estatal y de gestión autonómica- provocando que el crecimiento de sus colecciones se convierta en una gran dificultad ${ }^{11}$.

La Consejería de Cultura de la Junta de Andalucía tiene la misión de preservar los bienes culturales del Patrimonio Histórico Andaluz: "La Administración de la Junta de Andalucía velará, a través de la Consejería competente en materia de museos, por la protección, conservación, difusión y accesibilidad de los fondos existentes en los museos y colecciones museográficas de Andalucia""2. Por lo que el incremento de fondos está recogido dentro de las funciones básicas de los museos pertenecientes a este territorio. La inclusión de una pieza debe estar aprobada por la Comisión Andaluza de Bienes Muebles que se basa en los objetivos, medidas y proyectos del II Plan General de Bienes Culturales. Este Plan postula la política de adquisición de bienes en Andalucía como una medida de protección, valoración, investigación y documentación del patrimonio histórico ${ }^{13}$. En este sentido las nuevas demandas sociales en cuanto a la cultura son las que van a encaminar las nuevas líneas de actuación, incorporando obras contemporáneas a sus colecciones, adaptándose a los nuevos tiempos. Dando lugar al acercamiento y participación de la sociedad en la institución museística ${ }^{14}$.

Al igual que sucediera con la mayoría de museos de bellas artes, la formación del museo de Córdoba surge a partir de la Desamortización de 1835, cuando los bienes artísticos de los conventos y monasterios cordobeses fueron cedidos a la Comisión Artística y Científica en nombre del Estado. Sin embargo, la falta de administración, de recursos económicos y de un lugar donde establecer estos bienes, supuso que la mayoría de ellos fuesen trasladados en numerosas ocasiones. Posteriormente se crearía la Comisión de Monumentos Históricos y Artísticos, sucesora de las Comisiones Artísticas y Científicas. Es entonces cuando, en el año 1844, se procedió a la creación de un museo en la antigua sede de la Diputación, que dirigiría Diego Monroy Aguilera, el cual realizará el primer catálogo de esos bienes ${ }^{15}$. Pero los problemas empezaron a surgir desde el inicio, ya que se carecía de instalaciones y de espacios de almacenamiento y exhibición para desempeñar su funcionamiento. A consecuencia de ello, y por mandato de la real orden del Ministerio de Instrucción Pública y Bellas Artes, en 1862 el museo se estableció en el antiguo Hospital de la Caridad, un edificio desamortizado cuya construcción se inició a finales del siglo $X V^{16}$. A pesar del traslado a este inmueble, los problemas de espacio de esta institución no se solucionaron, ya que en el mismo edificio se establecieron también el Museo Arqueológico, la Escuela Provincial de Bellas Artes y la Escuela de Música; además de que se produjo un incremento de fondos a consecuencia de la desamortización de 1868 a lo que se sumaron diversas adquisiciones por parte de la Comisión de Monumentos y donaciones de particulares ${ }^{17}$.

Es a partir del siglo XX cuando el museo comienza a establecer la adquisición y el incremento de fondos como una de sus principales funciones. Partiendo de sus colecciones fundacionales, el museo pretende completar sus colecciones atendiendo a los objetivos

11 MARTINEZ LOMBÓ, 2009: 1-3.

${ }^{12}$ Ley 8/2007 de 5 de Octubre de Museos y Colecciones Museográficas de Andalucía, Art. 6. BOJA n ${ }^{\circ} 205$, 18 de Octubre del 2007.

13 MUDARRA BARRERO, 2003: 18-22.

${ }^{14}$ Ley 8/2007 de 5 de Octubre de Museos y Colecciones Museográficas de Andalucía, Art. 30. BOJA n 205, 18 de Octubre del 2007.

15 PALENCIA CEREZO, 1995: 16 -20.

16 AGUAYO MARMOLEJO, 2011: 13-14.

17 PALENCIA CEREZO, J.M.: Museo de Bellas Artes de Córdoba: guía oficial, Junta de Andalucía, Consejería de Cultura, 2003, pp. 20-38. 


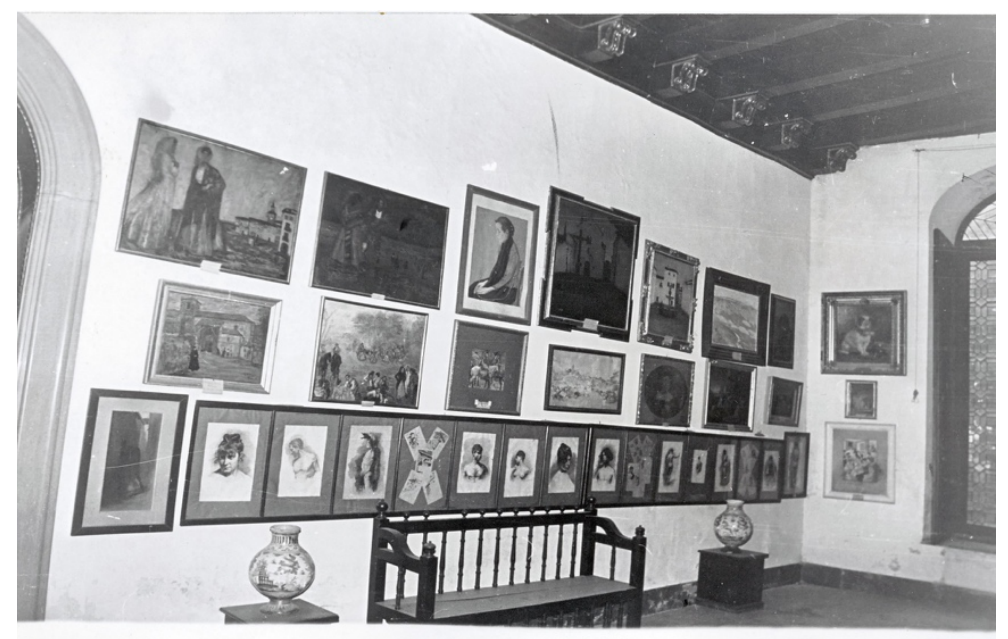

Fig. 1. Sala A. Sección de Arte Moderno del Museo de Bellas Artes de Córdoba, hacía 1980 (Facilitado por el Museo de Bellas Artes de Córdoba).

marcados por el Plan Museológico, se proponen piezas que tengan un valor histórico, artístico y documental y, además, que sean representativas del panorama cultural cordobés y andaluz. La institución museística al incrementar sus fondos debe plantear un discurso razonado, seleccionando las piezas con un juicio de valor y que doten a la colección de coherencia. Sin embargo, este acrecentamiento se convierte en una difícil tarea por la limitada disponibilidad de recursos económicos, por la falta de espacio en el edificio y por instalaciones que no permiten el idóneo desarrollo del museo ${ }^{18}$.

\section{La "sección de arte moderno" del Museo Provincial de Bellas Artes de Córdoba}

Para el desarrollo y difusión del patrimonio de Córdoba es decisiva la figura de Enrique Romero de Torres (1870-1956), ya que convertirá a esta ciudad en un exponente cultural. Este hijo predilecto de la ciudad cordobesa fue educado en un ambiente artístico gracias a su padre, Rafael Romero Barros, el cual se dedicó a la pintura, además de participar en el desarrollo del Museo de Bellas Artes de Córdoba, como Conservador-Restaurador. La familia Romero de Torres, durante el siglo XX, es la responsable de gestionar la cultura cordobesa, convirtiendo el antiguo Hospital de la Caridad en el epicentro histórico y artístico de la ciudad. Desde muy joven, Enrique comienza su carrera en las instituciones relacionadas con el patrimonio histórico-artístico de Córdoba, llevando a cabo numerosas actuaciones culturales y hallazgos arqueológicos. En 1902 es nombrado, por la Comisión de Monumentos, conservador-interino del Museo Provincial de Bellas Artes, y posteriormente formará parte de la Real Academia de Córdoba. En su labor como conservador, llevara la colección del museo de bellas artes a su mayor esplendor gracias a sus contactos con numerosos críticos y artistas del panorama nacional ${ }^{19}$.

En 1916 Enrique Romero es nombrado director del museo de Bellas Artes de Córdoba, y siguiendo con la labor de sus antecesores, se centra en las mejoras del museo. Durante los años veinte, lucha por la independencia del museo del resto de instituciones que se albergaban en el Hospital de la Caridad, con el objetivo de buscar más espacio para sus colecciones, ya que en esta década la colección de la institución tendrá un notable aumento, además se centrará en la conservación de los fondos y en la realización de un catálogo como método de difusión. Desde 1932 hasta su fallecimiento el 21 de mayo de 1956, consagra su

\footnotetext{
18 GARCÍA DE LA TORRE, 2003: 41-44.

19 PALENCIA CEREZO, J.M: Enrique Romero de Torres. Junta de Andalucía, Consejería de Cultura, Sevilla, 2006, pp. 16-50.
} 
carrera a la historia del arte y a su empeño constante de luchar por su museo y la gran colección que alberga ${ }^{20}$.

A finales del siglo XIX surgen diversas vertientes en cuanto a la planificación y gestión del museo. Sin embargo, la mayoría de instituciones museísticas españolas siguen rigiéndose por unos criterios obsoletos, convirtiendo a los museos en meros espacios de exhibición, donde se da prioridad al carácter estético de las piezas, dejando al margen su contexto y significación. "museos contenedores" dirigidos hacía expertos y eruditos que no daban cabida a la interpretación y a la didáctica ${ }^{21}$. Enrique Romero de Torres se esfuerza en renovar la imagen del museo primitivo surgido de la Desamortización y transformarlo en una institución renovada que albergase obras de artistas coetáneos. Este empeño tenía el objetivo de adaptar la institución a los parámetros del nuevo siglo, ampliando su colección hacía una dirección más contemporánea. Durante los viajes que realizó a la capital, hizo numerosas amistades con artistas del momento que donarían obras suyas al museo, al tiempo que ocasionalmente compraría algunas con su propio dinero. Además, la colección del Museo de Bellas Artes de Córdoba se enriquecería también con diversos depósitos del Museo de Arte Moderno 22 .

En 1902 surge, pues, la Sección de Arte Moderno que se instala en la sala que durante un tiempo estuvo destinada a la antigua Escuela Provincial de Bellas Artes. Esa colección se inaugura oficialmente el 10 de Enero de 1904 con obras de grandes artistas del panorama nacional como José Jiménez Aranda (1837-1903), Rafael Romero Barros (1832-1895), Ángel María Barcia y Pavón (1841-1927), etc. ${ }^{23}$ La denominación de esa colección reunida como "Sección de Arte Moderno", presenta cierta imprecisión y ambigüedad en cuanto al término, dado que "moderno" es utilizado en este caso asimilando al concepto de "modernidad" anglosajón, refiriéndose a lo más nuevo o coetáneo, si bien en España cuando se alude al "arte moderno", se hace referencia a las manifestaciones artísticas surgidas entre los siglos XVI y XVII. Sin embargo, para la nueva sección del museo se utilizaría como sinónimo de contemporaneidad y vanguardia, refiriéndose en concreto al arte realizado a partir del siglo $\mathrm{XX}^{24}$.

A partir del nombramiento de Enrique Romero como director se ejecutan numerosas reformas, destacando entre ellas, el descubrimiento y la restauración de la portada original de la Iglesia del Hospital de la Caridad, obra que se prolongará hasta 1931. Además, realiza numerosos cambios museográficos para dar cabida a las nuevas donaciones y adquisiciones. Paulatinamente va creando una colección representativa de las manifestaciones artísticas del momento, incrementando la Sección con obras de sus contemporáneos.

Durante la primera mitad del siglo XX, Enrique Romero luchó por incrementar los fondos del Museo Provincial de Córdoba, y hacer de él una institución renovada y modernizada. Tras su jubilación le sucedería en el cargo su sobrino e hijo de Julio Romero de Torres, Rafael Romero de Torres Pellicer -que anteriormente trabajaba como restaurador, iniciándose una etapa de declive para el museo. Durante esta época se sigue manteniendo la Sección de Arte Moderno, con una organización y estética decimonónica, y claramente ajenas a los nuevos avances que empezaron a surgir en los museos. El Museo de Bellas Artes presentaba una organización espacial, en cuanto a la exhibición y la colocación de las obras, bastante tradicional e historicista cuyo origen se retrotraía a concepciones de mediados del siglo XIX. Las obras se disponían sin un orden preestablecido, mezclando épocas y estilos ${ }^{25}$;

${ }^{20}$ Ibid pp. 88- 98

21 SANTACANA MAESTRE, J y SERRAT ANTOLÍ, N. (coord.): Museografía didáctica, Ed. Ariel., Barcelona, 2005, pp. 23-24.

22 PALENCIA CEREZO, J.M.: Museo de Bellas Artes de Córdoba: Guía oficial, Junta de Andalucía, Consejería de Cultura, 2003, pp.31-39.

${ }^{23}$ Cfr. Museo de Bellas Artes de Córdoba. Inventario de Pintura Moderna. José María Palencia Cerezo. 1996 [Consultado en: 01/9/2017]

24 ALONSO FERNÁNDEZ, L.: Museología: Introducción a la teoría y práctica del museo, Ed. Istmo S.A., Madrid, 1993 , p. 145.

25 RICO, J.C.: Montaje de Exposiciones: Museos, Arquitectura y Arte, Ed. Silex, Madrid, 2007, p. 363. 
no se atendía a los espacios, a la altura de la colocación o a la iluminación; y las piezas se acumulaban en las salas siguiendo una disposición geométrica, con el único criterio claro de buscar la simetría ${ }^{26}$. En la época de Enrique Romero de Torres y Rafael Romero de Torres Pellicer, la estructura expositiva resultaba bastante peculiar, ya que las piezas se disponían en varias hileras, instalando en la parte inferior la obra gráfica y en la parte superior la pictórica, siguiendo un concepto decorativo y geométrico. Sin embargo, es posible que la razón de exponer así, quizás respondiera a un problema de espacio y de almacenamiento.

El incremento de fondos, en cualquiera de sus formas, que realizan los profesionales de los museos en la actualidad están dirigidas hacía la investigación y la difusión. La institución selecciona las piezas según su relevancia dentro de la historia material del ser humano y buscando que, a su vez, se adapten a los criterios marcados en la política de colecciones. Sin embargo, los museos surgidos durante el siglo XIX coleccionaban todo, dando lugar a inconvenientes como la falta de almacenamiento para albergar las obras, incoherencias en la exhibición de las piezas y dificultades para organizar la colección a través del inventario o catálogo. En el caso del Museo de Bellas Artes de Córdoba, Enrique Romero no seguía ninguna pauta al adquirir obras para la institución, sino que seguía su gusto personal, creando en cierto modo una colección para sí mismo.

Desde la creación de la Sección de Arte Moderno en 1902 Enrique Romero, junto con la Diputación Provincial de Córdoba y el Patronato del Museo, fue adquiriendo piezas de los exponentes del arte español que desarrollaron su trayectoria artística en la primera mitad del siglo XX. Así, para su anexo de arte moderno adquirió en 1907 la obra Una gira Campestre del pintor montañés Francisco Iturrino González (1864-1924) datada a comienzos de siglo. Ese artista, formado en Lieja y Bruselas, pasa la mayor parte de su vida en Francia donde recoge la estética ligada al impresionismo y al fauvismo. Sin embargo, en 1901 viaja a Andalucía, donde queda fascinado por su luz y sus paisajes, marcando un cambio decisivo en su estilo. ${ }^{27}$ Una muestra de ello es el óleo que conserva el Museo de Bellas Artes, una escena costumbrista que, a pesar de estar abocetada, permite vislumbrar una novedad respecto a la pincelada, las tonalidades y el ritmo que crea en el lienzo. La obra de Francisco Iturrino fue ampliada en el museo con tres estampas realizadas aproximadamente durante 1907, aguafuertes que representan escenas cotidianas de la época: Corrida de Toros, Manolas paseando de noche, Bailando las sevillanas, etc., donde tendrá una fuerte presencia la figura femenina ${ }^{28}$.

En el mismo año, Enrique Romero compró un lienzo a José Gutiérrez Solana (18861945), exponente de la vanguardia española y figura de la generación del 27. La mayoría de sus obras son una muestra de la España Negra, con una visión grotesca e incluso macabra. Su obra Iglesia de Aldea. Ogarrio (Cantabria) (1906), muestra un paisaje rural, el cual llamo la atención de Enrique Romero por su semejanza a los paisajes y a la paleta de Valdés Leal ${ }^{29}$. De este artista madrileño se conservan también en la colección del museo tres reproducciones litográficas realizadas en 1935: La Murga gaditana, Barbería de Pueblo y El constructor de Carretas, donadas por el pintor cordobés Pedro Bueno Villarejo en $1996^{30}$.

En sus visitas a Madrid, Enrique Romero se relaciona con numerosos artistas y eruditos cordobeses que se habían establecido en la capital. Como es el caso de Adolfo Lozano Sidro (1872-1935), pintor nacido en Priego de Córdoba que viaja a Madrid en 1893 para desarrollar su incipiente carrera artística, además de trabajar como ilustrador en la

${ }^{26}$ RICO, J.C.: Manual práctico de museología, museografía y técnicas expositivas, Ed. Silex, Madrid, 2006, pp. 19-22.

27 MARTIN FERNÁNDEZ, 2004: 575-576.

${ }^{28}$ Colecciones: acceso a fondos del Museo de Bellas Artes de Córdoba, [DOMUS], nºE0431G, CE0435G, CE0434G. Andalucía: Consejería de Cultura de la Junta de Andalucía. http://www.museosdeandalucia.es/fondos-museisticos [Fecha de acceso: 15/07/2017]

${ }^{29}$ Colecciones: acceso a fondos del Museo de Bellas Artes de Córdoba, [DOMUS], no CE2492P, Andalucía: Consejería de Cultura de la Junta de Andalucia. http:/ / www.museosdeandalucia.es/fondos-museisticos [Fecha de acceso: 15/07/2017]

${ }^{30}$ PALENCIA CEREZO, 2007: 27-34 


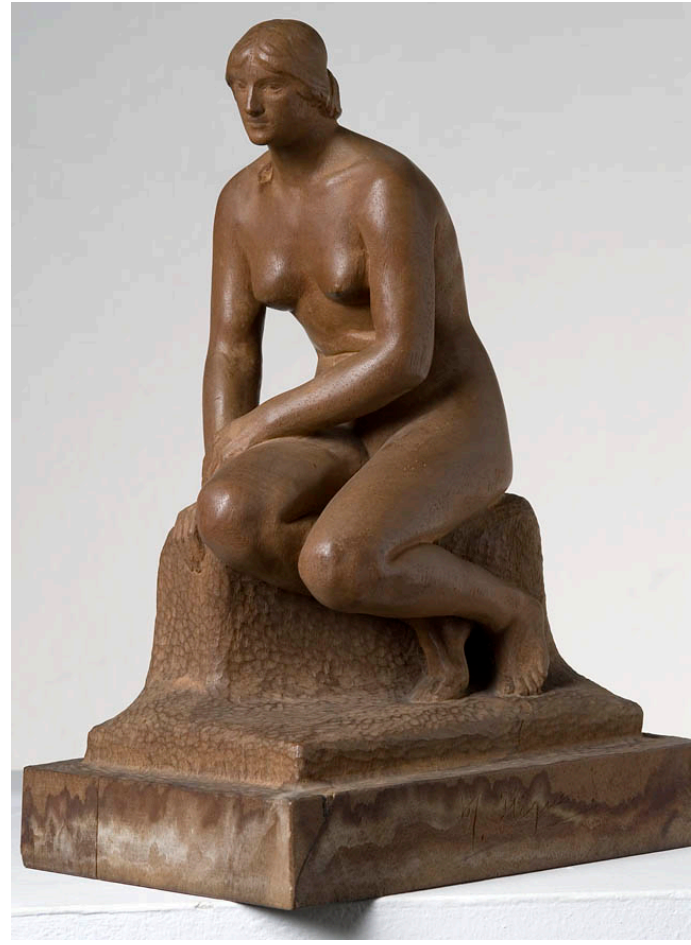

Fig. 2. La Gitanilla (h. 1900), Jacinto Higueras Fuentes, Bronce, (DOMUS: CE2651E)

Revista Blanco y Negro ${ }^{31}$. Lozano Sidro es conocido por sus numerosos retratos a personajes célebres, y por sus minuciosas representaciones del ambiente y de la sociedad de su época. En esas composiciones plasma escenas cotidianas, tanto del pueblo llano como de las grandes élites. Sus obras presentan un gran número de figuras, de las cuales cada una goza de su individualidad, con una gran precisión en la línea y el color. Así, Lozano Sidro es conocido como el "cronista total de su época" por su gran detallismo al representar la vestimenta, los ambientes, el mobiliario, el paisaje, etc. ${ }^{32}$. Interesado por este artista, fue en 1928 cuando Enrique -que viajó a Madrid por el centenario de la muerte de Goya- adquiriría la pintura de Lozano titulada Pequeña Fiesta, obra que data primera década del siglo XX y en la que se representa una reunión de una serie de personajes de la alta sociedad española, con una composición muy detallista y de aspecto modernista ${ }^{33}$.

En ese mismo viaje también contacta con su paisano Carlos Ángel Díaz Huertas (1866-1937), pintor cordobés que se trasladó a temprana edad a Madrid. Ángel Díaz trabaja durante un largo periodo como ilustrador para revistas de tirada nacional, siendo el primero que realiza la portada de la revista ilustrada Blanco y Negro. Por petición de Enrique, la Diputación compra al artista en el año 1933 una pequeña aguada titulada El Baño (1932) ${ }^{34}$.

Por lo que se refiere a la presencia en la colección de artistas andaluces que se centraron en el cultivo de la escultura, es importante mencionar una compra realizada durante esa etapa, concretamente en 1917, a Aurelio J. Sánchez de una pequeña pieza acabada en bronce y titulada La Gitanilla, obra del escultor jienense Jacinto Higueras Fuentes (1877-1954) ${ }^{35}$, que representa un desnudo femenino reposando sobre un pedestal.

\footnotetext{
31 ZUERAS TORRENS, 2000: 9-26.

32 JIMÉNEZ, 2014: 1-12.

${ }^{33}$ Colecciones: acceso a fondos del Museo de Bellas Artes de Córdoba, [DOMUS], n ${ }^{\circ} \mathrm{CE} 2680 \mathrm{P}$, Andalucía: Consejería de Cultura de la Junta de Andalucía. bttp:/ / www.museosdeandalucia.es/fondos-museisticos [Fecha de acceso: 15/07/2017]

${ }^{34}$ Colecciones: acceso a fondos del Museo de Bellas Artes de Córdoba, [DOMUS], noDO0007D, Andalucía: Consejería de Cultura de la Junta de Andalucía. http://www.museosdeandalucia.es/fondos-museisticos [Fecha de acceso: $15 / 07 / 2017]$

${ }^{35}$ Colecciones: acceso a fondos del Museo de Bellas Artes de Córdoba, [DOMUS], nºE2651, Andalucía: Consejería de Cultura de la Junta de Andalucía. http:/ / www.museosdeandalucia.es/fondos-museisticos [Fecha de acceso: 04/08/2017]
} 


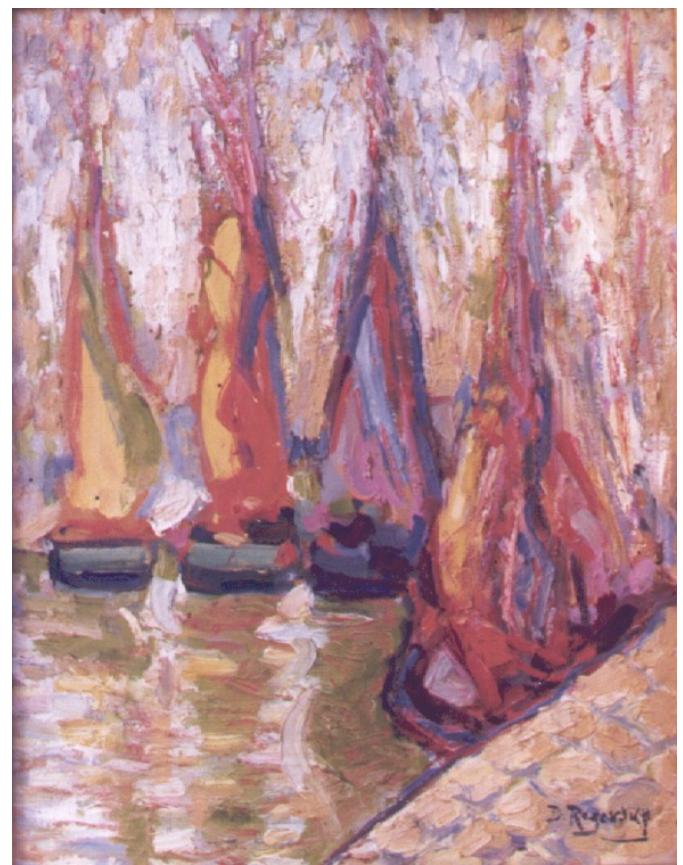

Fig. 3. Velas de Oriente (h. 1920), Dimitri Regevsky, Óleo sobre lienzo, (DOMUS: CE2512P)

En esta época el Museo de Bellas Artes de Córdoba sigue recibiendo numerosas donaciones gracias a los contactos de Enrique y de su hermano Julio. Entre ellas el Retrato de Hombre (1902) del valenciano Manuel Benedito Vives (1875-1963), obra donada en 1917, seguramente en una visita de Enrique a Madrid. Posteriormente, la celebración en 1919 de la primera exposición individual de Julio Romero de Torres en el Majestic Hall de Bilbao, favorecería que los hermanos crearan contactos con los artistas e intelectuales vascos contemporáneos, como fue el caso de Quintín de Torre Berastegui (1877-1966), quien por la amistad que le unía a Julio dona para la Sección de Arte Moderno su obra Cargador del muelle de Bilbao, una escayola modelada en 1906, que muestra un personaje masculino, de fuerte musculatura, representado de pie y ataviado con la ropa de trabajo, siendo buen exponente del característico interés de Torre durante su primera etapa por la clase popular y trabajadora $^{36}$. A partir de la mencionada exposición de Julio Romero, se recibieron otras donaciones para el museo, como la del pintor ruso Dimitri Regevsky, quien en 1920 donó el lienzo titulado Velas de Oriente, una marina con barcos ${ }^{37}$-temática muy popular de la épocarealizada con una pincelada suelta y pastosa con la que entremezcla las tonalidades. Se trata de una pieza que se pone en relación con tendencias artísticas francesas como el impresionismo y con maestros fauvistas como André Derain.

Unas de las obras más representativas e importantes de este museo provincial son los grabados de Ricardo Baroja Nessi (1971-1953), que fueron donados directamente a Enrique. El museo conserva un número de cincuenta y dos estampas, donadas en el transcurso de dos etapas, siendo la primera entre 1906 y 1909 y la segunda en 1910. Baroja fue uno de los representantes más significativos del grabado español de su época. Entre 1898 y 1912 realizó su mayor número de aguafuertes, complementados, en cuanto a técnica, con aguatinta y la punta seca. La temática de estos grabados es muy concreta, centrándose en los paisajes y la cultura popular de la España de su tiempo. Baroja tuvo una fuerte relación con los personajes de la vanguardia artística española, convirtiéndose en un firme representante de la generación del 98 y de la vertiente pictórica costumbrista. Es en este círculo intelectual donde Baroja establece una estrecha relación con la familia Romero de Torres, y especialmente con Julio

\footnotetext{
36 SOTO CANO, 2010: 21.

37 PALENCIA CEREZO, J.M: Enrique Romero de Torres. Junta de Andalucía, Consejería de Cultura, Sevilla, 2006, pp. 41-65.
} 
Romero. El museo, además conserva dos lienzos, Autorretrato (1910) y La Venta (1927), que fueron donados por el propio Baroja. Estas obras se enmarcan en la primera etapa del maestro onubense, en la que proliferan los retratos y los paisajes de sus numerosos viajes por España y Europa ${ }^{38}$.

Durante esta etapa se incorporan un gran número de grabados a la colección con nombres tan destacados como José Pedro Gil Moreno (1892-1945), quien 1935 donó diez grabados realizados como ilustraciones para una publicación francesa, Un soir à Cordone de G. Grappe en 1926. También el pintor mejicano Roberto Montenegro (1887-1968) tiene presencia en la colección, gracias a la donación en 1922 de tres grabados con una temática nacionalista y popular, pero dentro de su estética surrealista. Junto a ellos sobresale Rafael Pellicer Galeote (1906-1963), el cual dona en 1944 un aguafuerte titulado El relojero (1932) y posteriormente, en 1947, otros tres: El Cerezo (1936), Lluvia (1945) y Cantores (1946) ${ }^{39}$. En el 2015 se añadirán dos obras más de Rafael Pellicer al museo, Mujer (1926) y Bolera (1950).

Los fondos de arte contemporáneo se vieron también incrementados gracias a las grandes donaciones como la del pintor, político y escritor cordobés, Ángel Avilés Merino (1842-1924) en 1922. Quién dona 400 piezas de diversa índole, siendo la mayoría de artistas coetáneos $^{40}$. Para albergar esta colección Enrique adquiere una pequeña parcela contigua al museo donde situará el estudio y el taller de restauración, dejando libre una de las salas de la planta baja. Es en 1924 cuando se inaugura, oficialmente, la Sala Ángel Avilés ${ }^{41}$, con la función de albergar la Sección de Arte Moderno ${ }^{42}$. Dentro de esa colección destaca la fotografía de un dibujo realizado por el artista valenciano Joaquín Sorolla y Bastida (18631923). La pieza original denominada Cabeza de niño y datada hacia 1906, está dedicada a su amigo José Pedro Gil Moreno de Mora ${ }^{43}$. Por otra parte, la donación de Avilés incluía una colección de dibujos de gran calidad, siendo el caso del dibujo de Ramón Casas Carbó (18661932) Obrera Catalana realizada hacía $1901^{44}$.

El Museo Provincial continuó aumentando sus colecciones, centrándose en ampliar la de dibujos y creando una nueva de grabados, además de recibir constantemente obras de artistas coetáneos. Y sería en 1943, diecinueve años después de la muerte del escultor cordobés Mateo Inurria (1867-1924), cuando el Museo de Bellas Artes recibió su obra mediante un depósito del Ayuntamiento por solicitud de Enrique Romero. El museo le otorga una sala propia al escultor, mediante una petición de ampliar la sede. La Diputación obtiene dos casas contiguas al museo y se construyen cuatro nuevas salas. Esta transformación se encarga al arquitecto Rafael de la Hoz, proyectándose tres salas en la planta alta y una en la plata baja que albergará la colección de Inurria. Sin embargo, no fue hasta el 13 de enero de 1952 cuando la nueva distribución arquitectónica -que se mantiene hasta nuestros días- se presentó al público ${ }^{45}$.

El museo cuenta con más de cuarenta esculturas del maestro Inurria, junto con numerosos dibujos preparatorios. La colección de Inurria muestra una visión completa de la trayectoria artística del escultor, con obras tempranas como Un naufrago (1890) y de su etapa de madurez

${ }^{38}$ AA.VV., 1990: 1-4

${ }^{39}$ GARCIA DE LA TORRE, 2002: 36-37.

${ }^{40}$ LÓPEZ RODRÍGUEZ, JOSÉ RAMÓN: Historia de los Museos de Andalucia, Universidad de Sevilla, Sevilla, 2010, pp. 293-294.

${ }^{41}$ No se ha podido incluir una imagen de la sala por su baja resolución, pero puede verse en: "Córdoba, Museo Provincial. Sala Ángel Avilés de arte moderno" (entre 1927 y 1936), Antonio Passaporte, Archivo LOTY.

IPCE:

http://www.mcu.es/fototeca_patrimonio/Visor?usarVisorMCU=true\&archivo=LOTY/preview/LOTY09523_P.jpg

42PALENCIA CEREZO, J.M.: Museo de Bellas Artes de Córdoba: Guía oficial, Junta de Andalucía, Consejería de Cultura, 2003, pp. 40-42.

${ }^{43}$ Colecciones: acceso a fondos del Museo de Bellas Artes de Córdoba, [DOMUS] n ${ }^{\circ} \mathrm{CE} 1126 \mathrm{~F}$. Andalucía: Consejería de Cultura de la Junta de Andalucia. http:/ / www.museosdeandalucia.es/fondos-museisticos [Fecha de acceso: 1/08/2017]

45PALENCIA CEREZO, J.M: Enrique Romero de Torres. Junta de Andalucía, Consejería de Cultura, Sevilla, 2006, pp. 118-125. 


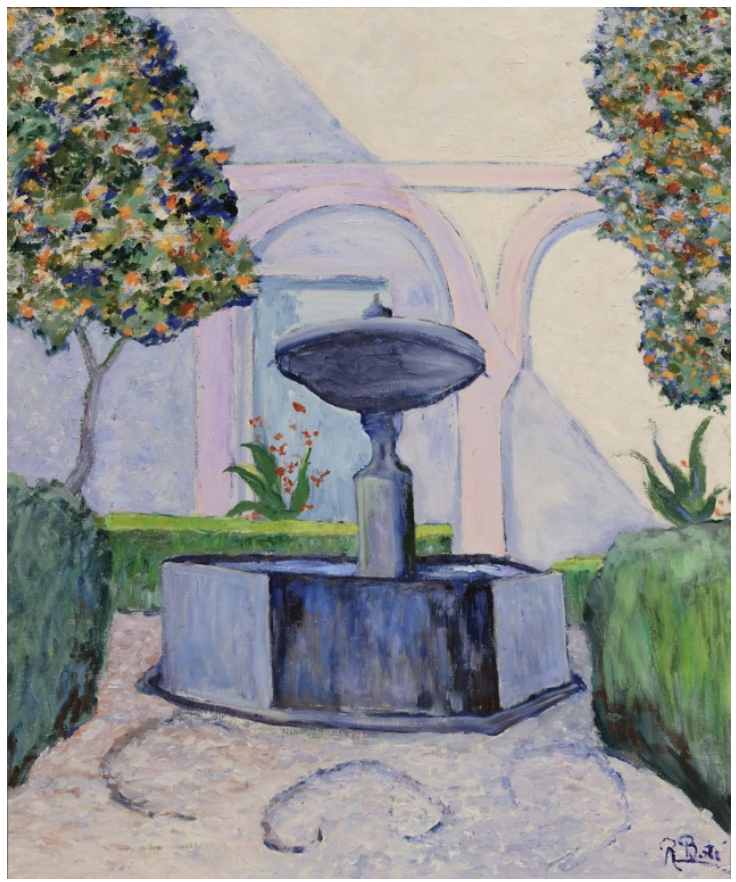

Fig. 4. La fuente del patio del Museo (1990), Rafael Botí Gaitán, Óleo sobre lienzo, (DOMUS: DJ0007P).

con La Parra (1920) o su conjunto de tres obras Las tres edades de la mujer (1923). Este depósito también alberga sus proyectos de Monumentos, teniendo gran relevancia la pequeña versión del Monumento a Antonio Barroso y Castillo (1918) en Córdoba, destruido en 1919. Al igual que la versión en bronce de la cabeza del Monumento al Gran Capitán (1923). La colección de Mateo Inurria, también estaba conformada con una serie de grabados de artífices europeos datados en los siglos XVII y XVIII, y algunas obras de artistas españoles ${ }^{46}$. En años posteriores la viuda de Inurria se pondría en contacto con el director del museo -cuando ya lo era Rafael Romero de Torres Pellicer-, para donar otro lote de obras.

En esta etapa los fondos de arte contemporáneo también se amplían a través de la donación del pintor Luis Bea Pelayo (1878-1963), gestión dividida en dos tiempos, siendo la primera entre 1948 y 1949 y la segunda en 1962, a su muerte. La colección está conformada por más de un centenar de pinturas, grabados y dibujos, y algunas esculturas ${ }^{47}$. Así, en 1949 se añadirán a la colección del museo tres grandes obras: La Dama del Lazo (1920) del propio Bea Pelayo, reconocida como su mejor obra; una escultura de Luis Benedito (1885-1955), hermano del pintor Manuel Benedito, titulada Antílope (h. 1920) y una pequeña escultura de escayola realizada por Juan Bautista Adsuara Ramos (1893-1973), Campesina, datada en $1942^{48}$.

\section{El Museo de Bellas Artes de Córdoba (1981-2012)}

Durante el siglo XIX los museos se desarrollan como instituciones donde albergar el conocimiento y como ejemplo del orgullo nacional. Sin embargo, el museo se ha ido adaptando a las transformaciones sociales, políticas y económicas que han surgido a lo largo de la historia, convirtiéndose en una institución variable. Los museos decimonónicos se consagran como "espacios sagrados", dirigidos hacía las clases más elitistas, hasta el surgimiento de la era post industrial donde se contempla una democratización de la cultura,

${ }^{46}$ MONTES RUIZ, R.: Mateo Inurria en el Museo de Bellas Artes de Córdoba. CajaSur Publicaciones, Córdoba, 1996, pp. 2-9.

${ }^{47}$ PALENCIA CEREZO, J.M.: Museo de Bellas Artes de Córdoba: Guía oficial, Junta de Andalucía, Consejería de Cultura, 2003, pp. 43 y 44.

48PALENCIA CEREZO, J.M: Enrique Romero de Torres. Junta de Andalucía, Consejería de Cultura, Sevilla, 2006, p. 125. 
a consecuencia del avance tecnológico y científico, junto la despreocupación de la sociedad por las necesidades básicas ${ }^{49}$. El patrimonio y las entidades cobran una gran importancia, incorporándose en los últimos años a las rutas del mercado del arte, creando así una beneficiosa industria cultural. Esta nueva sociedad del conocimiento muestra un gran interés por formar y entender su historia, dando lugar al surgimiento de una "revolución didáctica". Las instituciones culturales establecen medios que intermedien entre el espectador y el patrimonio, siendo los museos exponentes de divulgación y enseñanza. Estos organismos generan actuaciones y planteamientos museológicos y museográficos adaptados a la nueva sociedad, surgiendo nuevas teorías como la "museología crítica" y la "museografía didáctica" "50. Las acciones cambian, se llevan al límite, y se adaptan al servicio del objeto, las formas de traducir y comunicar el conocimiento deben corresponder a los programas didácticos. Por lo tanto, el objeto es contextualizado y se hace comprensible a través de la exposición, dejando de lado el concepto estético, y buscando el diálogo entre el objeto y el espectador. El objetivo de los museos del siglo XX es plantear el objeto de estudio en los principios didácticos ${ }^{51}$.

Al igual que suceden en numerosos puntos de España, en Andalucía se fragua la creación de nuevos museos, gracias al interés de instituciones políticas y culturales que pretenden fomentar el arte actual, amparado por la renovación de los ambientes artísticos que, a su vez, impulsan la creación de galerías a partir de los 60. Estas iniciativas progresan a través del Decreto del 24 de Julio de 1970 por el que se establece la creación el Museo de Arte Contemporáneo de Sevilla, una nueva institución que nace como apoyo al Museo de Bellas Artes, donde albergar el arte del siglo $\mathrm{XX}^{52}$. En Córdoba también florecen nuevos círculos intelectuales y artísticos a mediados de los años 50, a consecuencia de la aparición del edificio de la Cámara de Comercio e Industria de Córdoba en numerosas guías de arquitectura española del siglo XX y la posterior creación del grupo artístico Equipo 57. Sin embargo, con anterioridad, se realiza la primera exposición de arte contemporáneo en el Círculo de la Amistad en 1953. En este sentido, se produce el patrocinio de los nuevos lenguajes del arte por parte de los artistas e incluso de las instituciones, transformando a esta ciudad andaluza en uno de los epicentros del arte contemporáneo ${ }^{53}$. En este contexto el Museo de Bellas Artes de Córdoba se convierte en un espacio estático y sin pretensiones comparado con el panorama artístico de su época. El museo a manos de Rafael Romero de Torres Pellicer fue decayendo hacía un completo abandono, permaneciendo paralizado y clausurado entre 1978 y 1980.

A partir de 1981 el Museo de Bellas Artes de Córdoba recobra su actividad gracias a la intensa labor de Fuensanta García de la Torre (1952) la cual dedica gran parte de su vida al estudio, conservación y difusión de la colección del museo de Córdoba. A su llegada al museo en 1981, la institución se encuentra desprovista de instalaciones básicas como luz y agua, además de carecer de otros servicios necesarios para la correcta función del museo como talleres de restauración, almacenes, y sistemas de seguridad. Fuensanta García desde 1981 hasta 1986 lleva a cabo una fuerte transformación, para convertir ese espacio en el museo que es hoy en día. Desarrolla una completa remodelación de la infraestructura de la institución, a partir de un nuevo proyecto museológico y museográfico, siendo una ardua tarea por la evidente falta de espacio que posee la sede del museo. Este proyecto conlleva la creación de almacenes y sala de restauración, además de configurar nuevamente los espacios expositivos $^{54}$.

${ }^{49}$ GUASCH, 2008: 14-15.

50 SANTACANA MESTRE, J. y HERNÁNDEZ CARDONA, F.X.: Museología crítica, Ed. Trea S.L., Asturias, 2006., pp. 15-19.

51 SANTACANA MAESTRE, J /SERRAT ANTOLÍ, N. (coord.): Museografía didáctica, Ed. Ariel., Barcelona, 2005, pp. 20-22.

52 MARTÍN MARTÍN, 1990: 259-264.

53 PERÉZ VILLÉN, 2013: 12-32.

54 PALENCIA CEREZO, 2015: 17-20. 
Cómo se ha visto anteriormente, los museos no seguían un criterio objetivo al incrementar sus fondos. Sin embargo, con la nueva museología se marcarán unos límites y líneas de actuación precisas a la hora de coleccionar, atendiendo a una zona geográfica, un periodo, un artista, etc., con la finalidad de establecer una adecuada planificación en sus colecciones $^{55}$. En este sentido, el Museo de Bellas Artes centra su colección en un campo concreto -a saber, artistas que desarrollan su trayectoria artística en Córdoba-, con la finalidad de poseer un discurso museístico coherente y homogéneo.

El museo se moderniza y se adapta a los nuevos tiempos, apoyándose en las actuales teorías museológicas y museográficas. Transforma su gestión desde el interior e implanta la tecnología en las colecciones. Estas se incluyen en los catálogos digitales como la base "Red Digital de Museos Españoles", administrada por el Estado, y además también se incorporan en la plataforma DOMUS, un Sistema Integrado de Documentación y Gestión Museográfica desarrollado por el Estado e implantado por la Consejería de Cultura de la Junta de Andalucía. ${ }^{56}$. La informatización de las colecciones permite la difusión y la investigación de los bienes que el Museo de Bellas Artes de Córdoba alberga y conserva. En este sentido, la implantación de talleres didácticos y actividades culturales es primordial para la difusión del arte dirigido hacía la sociedad, que empieza a interesarse por el conocimiento y la historia. Se elaboraron numerosos talleres infantiles a partir de 1986 orientados a los centros docentes y a los visitantes individuales, con la finalidad de enriquecer la sensibilidad artística de los más pequeños. Desde 2006 se programan los talleres Sabadeo en el Museo y VeraneArte con la colaboración del Gabinete Pedagógico de Bellas Artes de las Delegaciones de la Educación y la Cultura de la Junta de Andalucía de Córdoba. Además de una singular e importante actividad en el Hospital Materno Infantil de la Ciudad Sanitaria Reina Sofía denominado Los niños del museo visitan a los niños del Hospita $\tilde{P}^{7}$. Junto a estos talleres, también se organizan actividades dirigidas hacía un público más adulto, como el proyecto "La obra del mes", realizado desde el 2003 hasta el 2012, siendo un ciclo que se repitió cada año con obras de especial interés para el público y el museo.

A lo largo del siglo XIX, los museos de bellas artes fueron incorporando a sus colecciones obras más contemporáneas, con la finalidad de mostrar las manifestaciones culturales que describían la sociedad del momento ${ }^{58}$. El museo de Bellas Artes de Córdoba ha buscado completar las lagunas existentes en sus fondos con manifestaciones artísticas que no estaban representadas en el museo, existiendo un vacío de las vanguardias históricas y una minoría de obras contemporáneas. Se debe tener en cuenta que a partir de los años 80 la introducción de piezas de arte contemporáneo en los museos va a estar directamente relacionadas con la producción disponible de los artistas coetáneos y con las complejas leyes del mercado ${ }^{59}$.

En 1984 el Museo de Bellas Artes de Córdoba pasa a ser gestionado por la Junta de Andalucía y a partir de este momento la colección se incrementara por medio del ingreso de fondos por parte de esta administración. Un gran número de los museos españoles sufren una peculiaridad al ser una institución de titularidad estatal y de gestión autonómica. Cuando la adquisición y la donación son realizadas por el Ministerio de Cultura, el objeto directamente pasa a pertenecer a la colección estable del museo, mientras que si el objeto es donado por o adquirido - en el caso del Museo de Bellas Artes de Córdoba, por la Junta de Andalucía - se incorpora en calidad de depósito dentro del museo formando parte de la Colección Museística de Andalucía. No obstante, podríamos decir que el Museo de Bellas Artes de Córdoba ha incrementado su colección mediante tres vías: la adquisición, el depósito

\footnotetext{
55 BELLIDO GANT, 2006: 82.

56 "Consejería de Cultura de la Junta de Andalucía, Fondos Museísticos". En: $<$ http://www.juntadeandalucia.es/organismos/cultura/areas/museos/fondos-museisticos.html $>[$ Fecha de acceso: $15 / 08 / 2017]$.

57 GODOY DELGADO, 2007: 43-53.

58 BELLIDO GANT, 2006: 82

${ }^{59}$ MUDARRA BARRERO, 2003: 17.
} 
Fig. 5. "Último Espacio Verde" (1991), Antonio Bujalance Gómez, Óleo sobre lienzo, (DOMUS: DJ1420P)

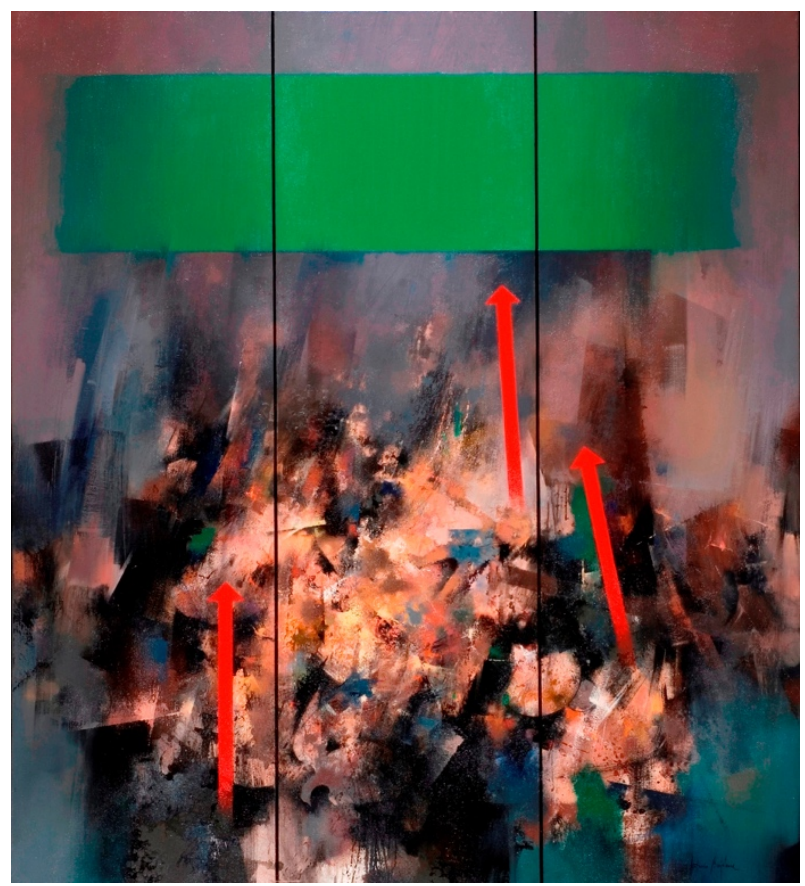

y la donación, excepto en algunos casos que han sido de "Producción Propia" algo inusual en un museo de bellas artes, siendo un ejemplo de ello el dibujo Angel del cordobés José Luis Muñoz Luque (1969), ejecutado con ocasión de las actividades de difusión realizadas en $2005^{60}$.

Conforme se han ido acrecentado los fondos de arte contemporáneo en el museo, se desarrollan numerosas exposiciones con un fin divulgativo y didáctico. En este sentido la primera muestra de arte contemporáneo que se realiza durante esta nueva etapa es "Arte Contemporáneo en Córdoba. Los fondos del museo" a finales de 1990. Diez años más tarde, se exponen las obras gráficas del museo relacionadas con los nuevos lenguajes artísticos, en una muestra titulada "Sobre papel: arte cordobés contemporáneo" con obras de José María García Parody, José María Báez, Dorothea von Elbe, entre otros. En la misma línea se realizó en 2003 la exposición "Dibujos. Adquisiciones y donaciones (1992-2003) y en 2005 "Grabado español del siglo XX". Posteriormente, el incremento de colecciones vuelve a hacerse visible en el 2008 con la exposición "Museo de Bellas Artes de Córdoba. Incremento de colecciones (1986-2006)", de la que se elabora un exhaustivo catálogo.

Durante esta etapa las donaciones al museo se gestionan a través del Ministerio de Cultura y la Junta de Andalucía, y normalmente se producen tras la celebración de exposiciones temporales. La mayoría de estas ofertas son representaciones contemporáneas del panorama artístico andaluz y cordobés. Gestionado por el Ministerio de Cultura, destaca la donación del artista Desiderio Delgado Chavaría (1955) de su óleo Mirador (1986). Por parte de la Junta de Andalucía se efectúan un mayor número de donaciones. En primer lugar, la exposición Gráfica Andaluza celebrada en 1988, dio lugar a la donación de cuatro estampas, ejecutadas expresamente para la ocasión, de los artistas Antonio Damián, Rafael Pérez Cortes (1961), Jacinto Lara Hidalgo (1953) y Fernando Baños (1948), y una fotografía de Clemente Delgado (1951). Esta exposición muestra las tendencias conceptuales en las artes gráficas que estaban desarrollándose en los años 80 en Andalucía. Las obras fueron aceptadas por la Consejería de Cultura mediante Orden de 13 de mayo de 1994. Es en este año cuando se produce una afluencia de donaciones contemporáneas, que permiten al museo ofrecer al espectador una retrospectiva del arte de su tiempo. Algunas de las donaciones parten de

${ }^{60}$ GARCÍA DE LA TORRE, 2007: 8-10. 


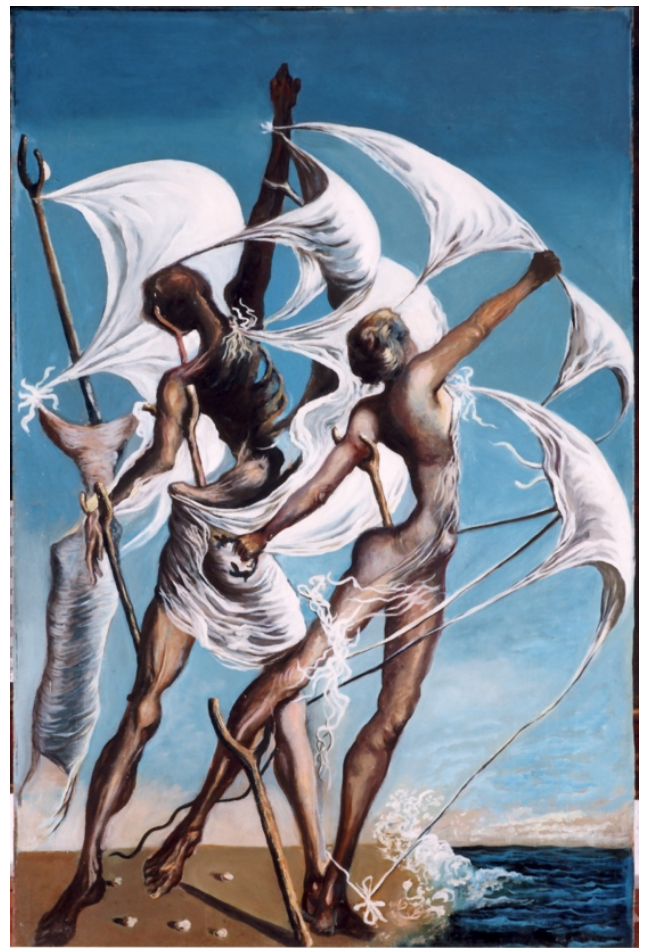

Fig. 6. Mujeres Vela (1934-1945) Antonio Rodríguez Luna, Óleo sobre tabla, (DOMUS: DJ1414P)

exposiciones temporales de los artistas, como la muestra de 1994 Momentos Cordobeses de Rafael Botí Gaitán (1900-1995), que donó La fuente del patio del Museo (1990) (Fig. 4) De este autor también se conserva en el museo un dibujo realizado en 1963, Boceto para Córdoba Callada. Asimismo, son relevantes las donaciones de José María Báez (1949), quien tras su exposición Sommaremmed Monika de 1987 en el museo, donaría en el año 1994 una docena de obras, aceptadas mediante Orden de la Consejería de Cultura el dos de mayo de 1996. Estas obras son un ejemplo de su etapa de mayor producción entre los 80 y los 90, donde la pintura y la escritura se unen, y entre ellas sobresalen Victoria (1968), De Kooning (1983), Tenazas (1984), Tenedor (1984), INRI (1985-1988), Algún instante (1949), Lápida (1991) y Licht (1991) Durante esta etapa el museo recibe también obras de la artista alemana Dorothea von Elbe (1941), criada en Estados Unidos y afincada en Córdoba desde 1986. Esta artista dona seis obras, "un grabado donado en 1987, y dos pinturas, y tres dibujos en 1994" en las que predominan los motivos naturales y la poesía. Del círculo artístico gaditano, el museo conserva dos obras del pintor José María García Parody (La Línea de la Concepción, 1951), el cartel para su exposición en el museo celebrada en 1989 y la obra Chimeneas (1987) donada por el propio autor en $1994^{62}$.

La colección de fotografía contemporánea del Museo de Bellas Artes de Córdoba, se forma gracias a la exposición realizada en 1995, Museo Latente, con motivo de la celebración del 150 aniversario de la institución. Cada artista dona alguna de las obras fotográficas que habían sido exhibidas. Entre ellos, Tete Álvarez (1964) con su obra Museum, Antonio Jesús González (1968) dona Reflexión de Antonio Jesús, José Carlos Nievas (1966) deja dos obras de su serie Sé que estás ahí, y por último Manuel Ángel Jiménez (1960) entrega al museo dos obras de su serie Tierra de Todos, Tierra de Nadie.

En 1996 se produce una implicación ciudadana con la cultura y el museo, a través la donación de un dibujo a carboncillo, Bodegón (1986), de Desiderio Delgado por parte de un grupo de cordobeses. Más tarde, en el año 2006, Antonio Bujalance Gómez (1934) dona dos obras realizadas en la década de los 90, Último Espacio Verde (Fig. 5) y Paisaje para los últimos

${ }^{61}$ PALENCIA CEREZO, 2007: 32-34.

${ }^{62}$ Ídem. 


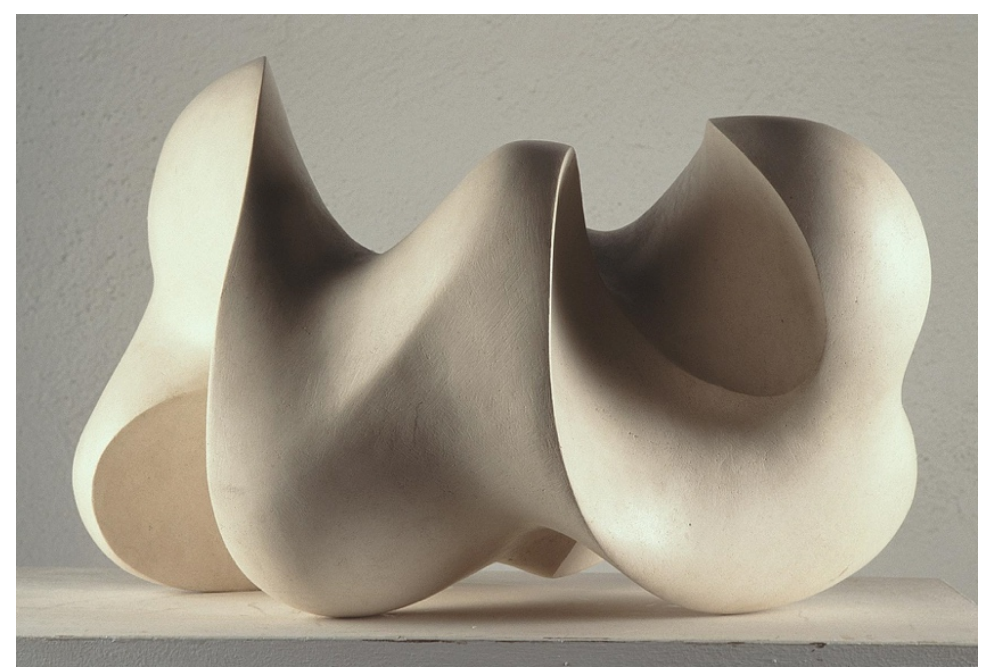

Fig. 7. S/T (1961), Equipo 57, Piedra, (DOMUS: DJ0032E)

pájaros, dos lienzos abstractos y coloristas pertenecientes a su última época, donde comienza a realizar las composiciones a base de texturas.

Con la llegada del nuevo milenio la Consejería de Cultura de la Junta de Andalucía adquiere numerosos bienes, para posteriormente depositar las obras en el museo. La mayoría de estas adquisiciones tienen el objetivo de crear una muestra del arte del siglo XX en las colecciones del Museo de Bellas Artes de Córdoba. El 10 de mayo del 2000 la Consejería de Cultura adquiere a Alcalá Subastas el dibujo Oterito de Ignacio Zuloaga Zabaleta (1870-1945). Este pequeño dibujo representa a la artista Eulalia Franco durante su estancia en París en 1936. Posteriormente, con la finalidad de acrecentar los fondos de la vanguardia artística andaluza, la Consejería de Cultura compra a la sevillana casa de subastas Arte, información y gestión, una obra del artista cordobés Antonio Rodríguez Luna (1910-1985). El museo no llega a acoger ninguna pieza de este artífice montoreño hasta el 2003, ya que la mayoría de su producción artística se conserva en México y en el museo que le ha sido dedicado en su ciudad natal. La obra que es adquirida para el Museo de Bellas Artes se trata de un conglomerado sobre madera titulada Mijeres Vela del que aún no se ha estimado su datación exacta, situándolo entre 1934 y $1945^{63}$ (Fig. 6).

Hasta el 2000, el Museo de Bellas Artes no contaba con una representación en sus fondos del Equipo 57, grupo colaborativo de artistas interdisciplinares, que parte de los primeros proyectos de los artistas cordobeses José Duarte y Juan Serrano como el Grupo Espacio o el Grupo Experimental de Córdoba. De estos postulados surge el Equipo 57 formado por los artistas vascos Agustín Ibarrola (1930) y Jorge Oteiza (1908-2003), el extremeño Ángel Duarte (1930-2007) y de los ambientes artísticos cordobeses forman parte de este grupo José Duarte (1928-2017), Juan Serrano (1929) y Juan Cuenca (1934). Tras su exposición en el café Le Rond Point de París, las manifestaciones del Equipo 57 unen el arte y el diseño bajo el trabajo en grupo. Sus obras desarrollan la teoría de la interactividad en el espacio plástico, a través de una preponderancia de la línea que delimita el color, destacando la importancia de los planos. A pesar de su corta existencia -ya que el grupo se disolvería en 1961-, tuvo un papel decisivo en la abstracción española igualándose a otros grupos artísticos del panorama nacional como Dau al Set o El Paso. La Consejería de Cultura adquiere seis dibujos datados entre 1959 y 1967, dos lienzos y una escultura de 1961 a la galería Rafael Ortiz (Fig. 7).

63PALENCIA CEREZO, 2007: 27-34 


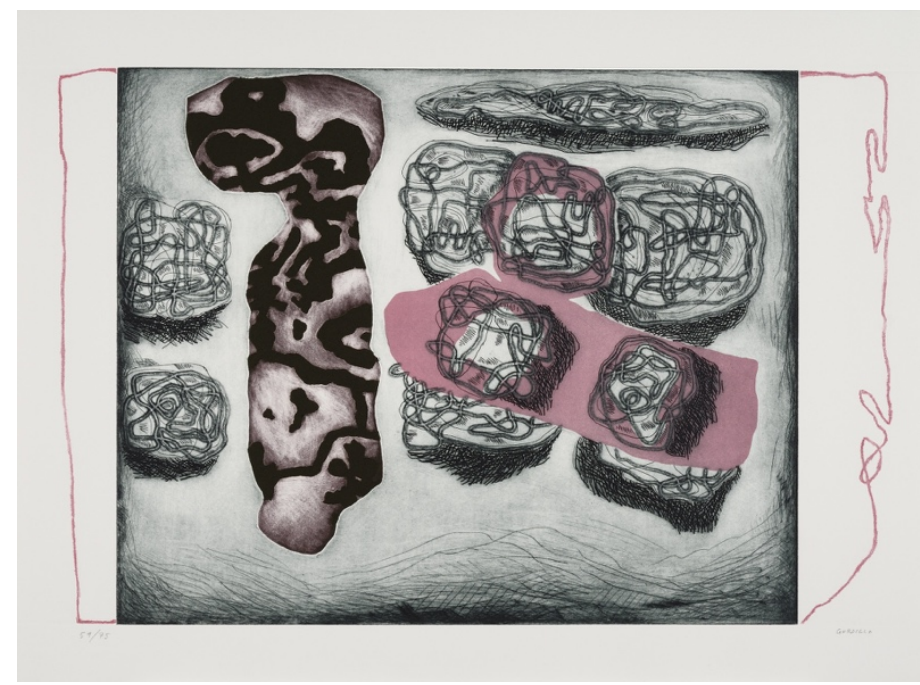

Fig. 8. Yo recuerdo que... (1985), Luis Gordillo, Lápiz sobre papel, DJ0105G

A estos fondos se le añade la donación del posterior director del museo, José María Palencia Cerezo, de un guache y grafito en 2003 -aceptado mediante Orden de la Consejería de Cultura de 7 de septiembre de 2004-, una interesante obra realizada tanto en el anverso como en el reverso, ejecutada en 1959. Por último, en 2004 la Junta de Andalucía adquiere el dibujo Pinocchio (1988) del cordobés Pepe Espaliú (1955-1993) a la casa de subastas Segre de Madrid. A pesar de las numerosas propuestas del museo, solo se ha conseguido este boceto a carboncillo y sanguina, realizado para una serie de 16 obras. A pesar de ser un pequeño boceto, la huella de Espaliú está presente a través del simbolismo, el juego de lo oculto y la doble identidad ${ }^{64}$.

Los bienes culturales que se incorporan a los fondos del Museo de Bellas Artes de Córdoba mediante depósito entre 1981 y 2012, se han realizado por administraciones públicas como el Ministerio de Cultura y la Junta de Andalucía. Excepto algunos depósitos realizados por particulares ${ }^{65}$.

La gráfica contemporánea se hace un hueco en el museo con la llegada de varias piezas de los "Premios Nacionales de Artes Plásticas" creados por Ministerio de Cultura en 1980, con el fin de dar reconocimiento a la creación contemporánea española que refleja los valores de la sociedad actual, y así mismo, contribuyendo a incrementar el patrimonio artístico de España ${ }^{66}$. Las carpetas, compuestas de cincuenta y nueve grabados y estampas de los premiados entre 1980 y 1985, son depositadas en el museo por la Dirección General de Bienes Culturales de la Junta de Andalucía en 1985, celebrándose ese mismo año una muestra temporal sobre ellas en el Museo de Bellas Artes de Córdoba. De este conjunto sobresalen obras de los artistas andaluces Luis Gordillo (1934), el cual presenta dos aguafuertes, Yo recuerdo que... (Fig. 8) y Diez nostalgias y un olvido; José Caballero y Muñoz-Caballero (1916), con dos aguafuertes de su serie Cuerdas; y del gaditano Guillermo Pérez Villalta (1948), con dos aguafuertes Fama y Fortuna. Junto a ellos también se sitúan artistas de importancia nacional como Rafael Canogar (1935) que ejecuta dos grabados realizados en aguafuerte y

\footnotetext{
64 PALENCIA CEREZO, 2007: 29-32.

${ }^{65}$ GARCÍA DE LA TORRE, 2007:11-12.

66"Ministerio de Educación Cultura y Deporte: Premio Nacional de Artes Plásticas".En:

$<\underline{\text { https://www.mecd.gob.es/cultura/areas/promociondelarte/mc/premiosbbaa/pn-artes }>[F e c h a ~ d e ~}$ acceso:15/08/2017]
} 


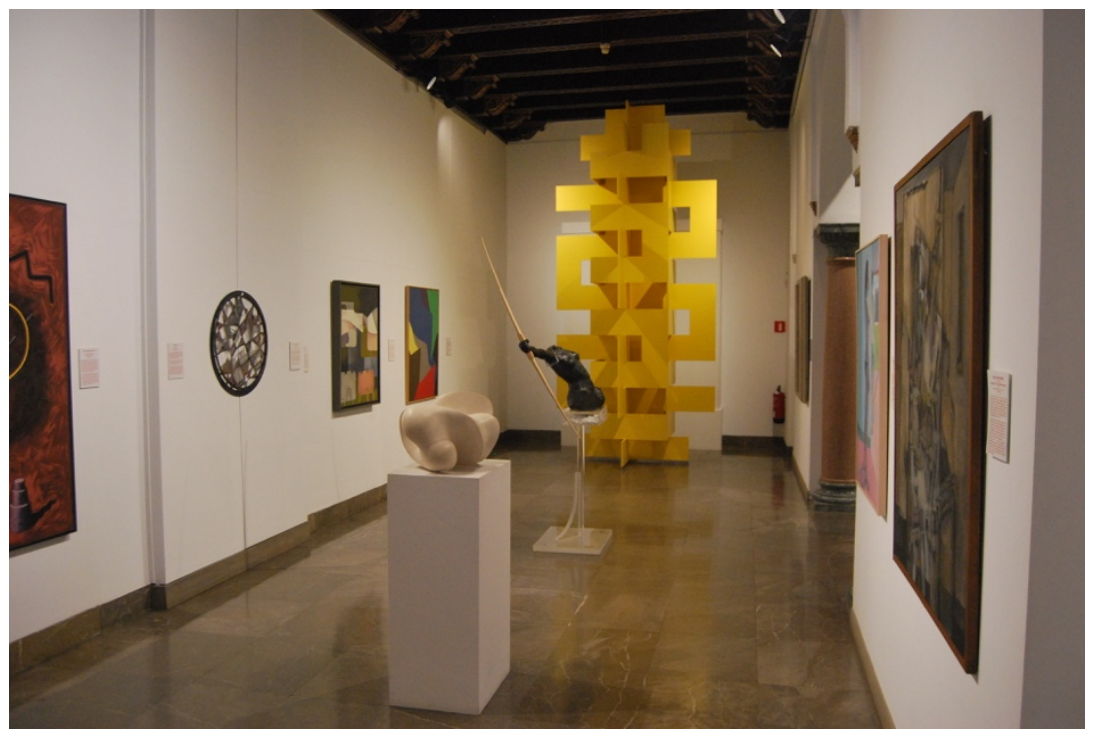

Fig. 9. Sala VI, “Arte Cordobés del siglo XX" del Museo de Bellas Artes de Córdoba (Facilitado por el Museo de Bellas Artes de Córdoba)

lápiz acuarelable, titulados El Caminante y Máscaras. Y del extremeño Juan Galea Barjola (1919-2004), se recogen dos aguafuertes denominados Camarin y Palco ${ }^{67}$.

La colección de grabados también se vio enriquecida con el depósito de otras tres carpetas. Siendo la primera una carpeta de veinticuatro obras, perteneciente al conjunto Homenaje a la Declaración Universal de Derechos Humanos (1984-1985) el cual comenzó en 1984, con la decisión de diversos organismos públicos de que un grupo cooperativo de artistas ilustren los artículos de la Declaración de Derechos. La carpeta fue depositada en el museo de Córdoba por la Delegación Provincial de la Consejería de Cultura en 1987, y con ella se llegó a realizar una exposición en el Archivo Histórico Provincial de Córdoba. Contaba con obras de autores como Rufino Tamayo (1899-1991), Roberto Matta (1911-2002), Antoni Clavé Sanmartí (1913-2005), José Guerrero (1914-1991), Robert Motherwell, (1915-1991) Antoni Tápies (1923), Eduardo Chillida (1924-2002), Julio LeParc (1928), Antonio Saura (1930-1998) y Rafael Canogar (1935). Por otro lado, entre 1984 y 1985, se realiza la Carpeta Testamento Andalur, a manos del escritor Antonio Gala, el músico Manolo Sanlúcar y el pintor Manuel Rivera (1927-1995), supliendo así la falta de obras en el museo del pintor granadino. Esta carpeta fue depositada en el Museo de Bellas Artes por la Delegación Provincial de la Consejería de Cultura en Córdoba, en el mismo año que la anterior. La carpeta está dedicada en su totalidad a homenajear la comunidad autónoma de Andalucía, "tratando veinticuatro lugares comunes del paisaje y del patrimonio histórico andaluz", a través de la pintura de Rivera, la poesía de Antonio Gala y la guitarra flamenca de Sanlúcar. Representado a Córdoba se disponen tres reproducciones en facsímil sobre cartulina, junto con sus correspondientes poemas, tituladas Mezquita de Córdoba, Sierra de Córdoba y Medina Azahara. Una tercera carpeta completaría la colección de grabados, a saber, la carpeta Andalucía, Sueño y Realidad (1990), realizada por los artistas Jesús Tejedor Vicente (1952) y Rashid Diad (1951), donde transforman los poemas de otros autores en manifestaciones plásticas contemporáneas. Esa carpeta estaba patrocinada por la Junta de Andalucía, depositándose en el museo en 1990 por la Dirección General de Bienes Culturales. De Rashid Diab se conservan nueve aguafuertes, mientras que del grabador zamorano doce. ${ }^{68}$ 


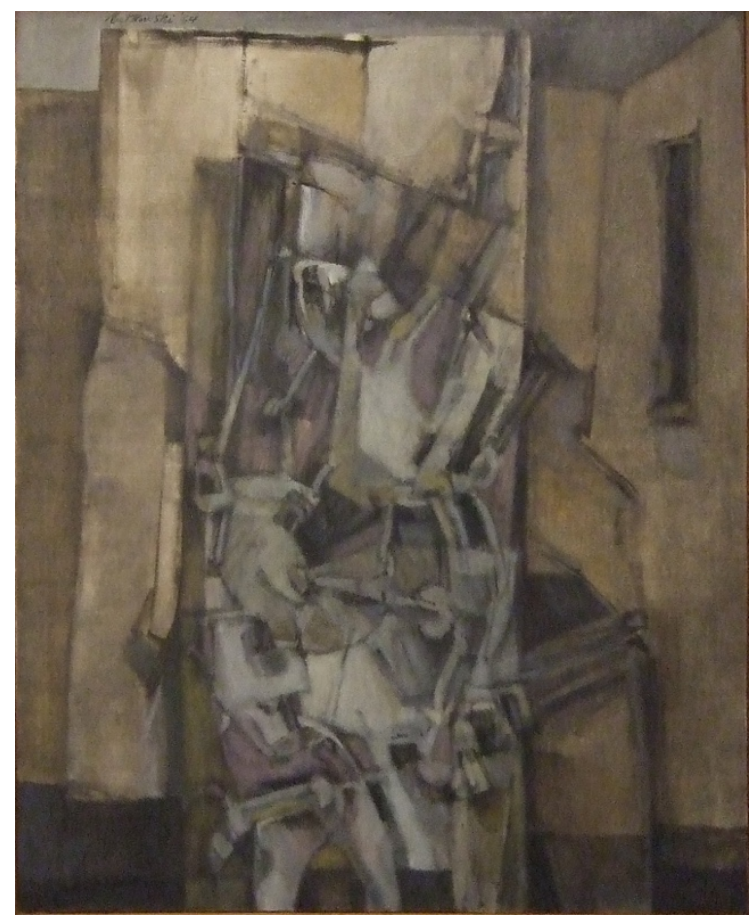

Fig. 10. Imágenes en la calle (Street Images) (1958-1964), Rita Rutkowski, Oleo sobre lienzo, (DOMUS: DJ1552P)

En cuanto al resto de colecciones, en 1993 la Delegación Provincial de la Consejería de Cultura de Córdoba adquiere a José María Córdoba (1950) un lienzo titulado Demasiado Tarde donde se plasma la temática del tiempo bajo la filosofía de la "Deconstrucción", y la reconversión de estilos artísticos como el cubismo, el surrealismo o el pop-art. Esta obra fue depositada en el museo, hoy en día está expuesta y situada en la sala dedicada al arte contemporáneo $^{69}$. Posteriormente, en el año 2003 , la colección de dibujos vuelve a crecer a partir de la adquisición de la Junta de Andalucía a un particular de diez dibujos del cordobés Alfonso Ariza (1920-1989). Y en cuanto a los fondos de escultura es relevante la donación de Juan Serrano Muñoz (1929) a la Junta, que la incorpora al museo mediante depósito en 2012. La obra en cuestión es una torre de madera lacada en amarillo, donde se aprecian los conceptos geométricos que este escultor cordobés ha desarrollado durante toda su carrera artística $^{70}$.

\section{El Museo de Bellas Artes de Córdoba en la actualidad}

Tras la jubilación de Fuensanta García de la Torre, el Museo de Bellas Artes de Córdoba sigue desarrollando la tarea de divulgación en materia de arte contemporáneo. En el 2013 el museo pasa a ser dirigido por José María Palencia (1959), el cual ha realizado un constante esfuerzo en la mejora del patrimonio cultural, junto con su principal interés por las manifestaciones pictóricas de artistas cordobeses de los siglos XVI al XX.

En la actualidad el museo reserva una sala a las manifestaciones contemporáneas, denominada "Sala VI, Arte Cordobés del siglo XX", las cuales comparten espacio con las obras del escultor Mateo Inurria. En esta sala se muestran obras de los exponentes de los nuevos lenguajes artísticos en Andalucía que empezaron a desarrollarse en el siglo XX (Fig. $9)$.

${ }^{69}$ Colecciones: acceso a fondos del Museo de Bellas Artes de Córdoba, [DOMUS] nºDJ0003PAndalucía: Consejería de Cultura de la Junta de Andalucía. bttp:// www.museosdeandalucia.es/fondos-museisticos [Fecha de acceso: 15/08/2017]

${ }_{70}{ }^{\circ} \mathrm{El}$ Museo de Bellas Artes, Colecciones: Incrementos del PH". En:

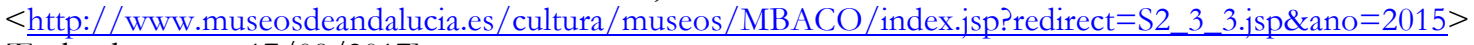
[Fecha de acceso: 17/08/2017]. 
Al igual que en la etapa anterior, el museo llevo a cabo numerosas exposiciones donde el arte contemporáneo es el protagonista. Además, respecto a la difusión, esta institución continua con la implantación de talleres y actividades, añadiendo en el 2013 el ciclo "El artista presenta su obra", que se ha prolongado hasta la actualidad, con la finalidad de revalorizar, difundir y divulgar el arte contemporáneo de los artistas con trayectoria de raíces cordobesas. A través de una presentación de la obra y un debate, se asiste a la iniciativa de convertir el museo en una sede para el arte actual.

Los bienes se incorporan en las colecciones a través de las donaciones realizadas a la Junta de Andalucía que son recibidas en el museo en depósito, a lo que se añaden los depósitos realizados por particulares. En el primer caso, la institución recibe la donación de la artista Rita Rutkowski (1932), la cual desarrolla su trayectoria artística en Córdoba desde los años 50. La donación de la artista es aceptada por Orden de la Consejería de Educación, Cultura y Deporte de 17 de abril de $2015^{71}$. Se trata de un conjunto de bienes marcados por la filosofía existencialista que Rutkowski tratará durante toda su carrera. Se conservan obras de su primera etapa en la ciudad como Imágenes en la calle (1958-1964) (Fig. 10) y Campo de la Verdad (1963), de influencia expresionista y surrealista, donde realiza un estudio de experimentación sobre la máquina y el movimiento que esta genera, mediante la abstracción. De los 70 destacan dos lienzos de su serie La persistencia de cierta imagen (1976), donde esboza la misma figura tratada desde distintas tonalidades e iluminación, aunque ambas evocan un exacerbado dramatismo, un cuerpo descompuesto que carece de la suficiente autonomía para existir por sí solo, mostrándonos su interior y dejando al descubierto los entresijos de la existencia. La mayoría de obras que Rita Rutkowski dona son de la década de los 80, en la que sobresale la serie The Crash, inspirada en el pop art y el fotorrealismo norteamericano. Rita representa automóviles después de sufrir un impacto, resaltando esas formas distorsionadas que resultan del choque, remitiéndonos al concepto de la fragilidad de la existencia, algo que ha estado presente en toda su trayectoria artística, pero que esta vez lo realiza con muchísima fuerza ${ }^{72}$. Dentro de esta etapa es importante su díptico El año de Halley (1986) donde las líneas son succionadas por el lienzo, las tonalidades se entremezclan dando lugar a que las formas se fundan ${ }^{73}$. A través de esta donación se elabora una muestra de su obra el 8 de marzo del 2017, coincidiendo con la celebración del Día de la Mujer.

Alfonso Blanco, uno de los restauradores del Museo de Bellas Artes hasta 2008, dona, en $2012^{74}$, once dibujos ejecutados por el artista gaditano José María García Parody (1951), pertenecientes a un cuaderno que le había sido regalado con motivo de la finalización de la restauración de una obra de Valdés Leal. En este cuaderno de dibujos, Parody escribe la palabra "ENHORABUENA", colocando cada letra acompañada de una imagen en una página, hasta sumar once. Cada una de esas letras capitales está decorada con una franja negra, recurso frecuente en la obra de Parody ${ }^{75}$.

Asimismo, la Colección de Dibujos y Grabados se enriquece mediante una donación, realizada el 29 de abril del 2015, por José Duarte Montilla (1928-2017). Nacido en Córdoba, Duarte se dedica en un primer momento a la enseñanza, formando parte de la "Escuela Experimental de Córdoba", posteriormente denominada "Grupo Córdoba". Años después se convierte en uno de los cofundadores del Equipo 57 y participante del movimiento de Estampa Popular. Su donación consta de una estampa con la técnica de linograbado, titulada Pavo muerto (1966),que pertenece a su época de Estampa Popular en la que realiza piezas de

\footnotetext{
${ }^{71}$ "El Museo de Bellas Artes, Colecciones: Incrementos del PH". En: $<$ http://www.museosdeandalucia.es/cultura/museos/MBACO/index.jsp?redirect=S2_3_3.jsp\&ano=2015 $>[$ Fecha de acceso: 17/08/2017].

72 RABASCO POZUELO, 2013: 3 y 4.

73 PÉREZ VILLÉN, 1998: 14-15.

${ }^{74}$ Las obras donadas por Rita Rutkowski y Alfonso Blanco fueron depositadas en el museo a lo largo del 2012, aunque la aprobación de su donación por la Junta de Andalucía no se llevó a cabo hasta 2015.

75 "El Museo de Bellas Artes, Colecciones: Incrementos del PH" En: <http://www.museosdeandalucia.es/cultura/museos/MBACO/index.jsp?redirect=S2_3_3.jsp\&ano=2015 $>$ [Fecha de acceso: 18/08/2017].
} 
Fig. 11. Artemisa despojada del chándal (2016), Juan Zafra, Terracota y Metacrilato,

(DOMUS: DO0203E)

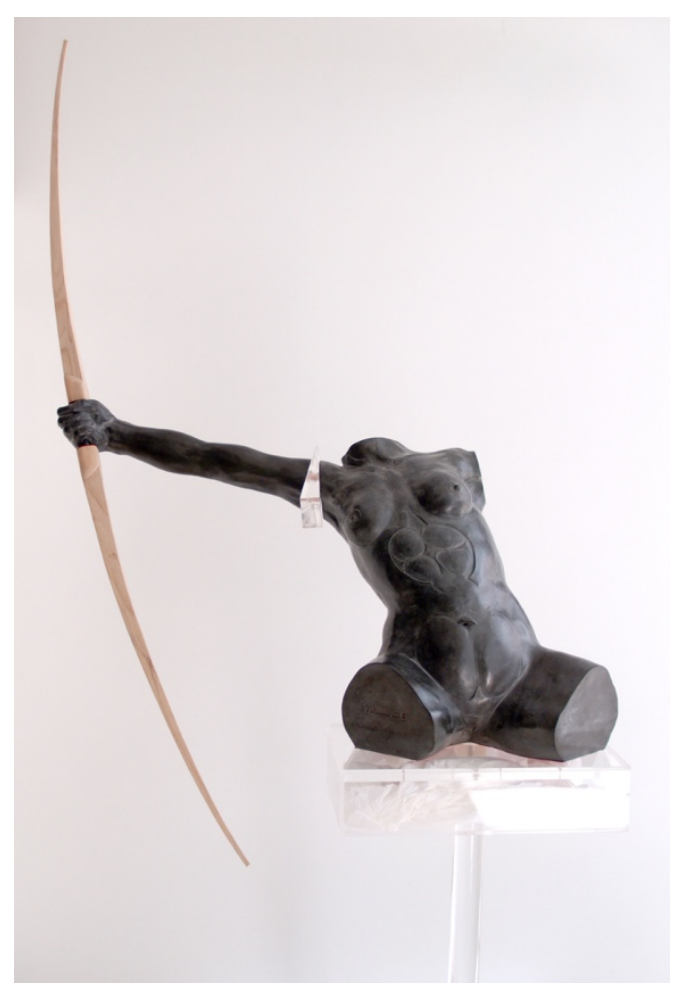

temática social, así como de un dibujo realizado en grafito, Mujer de espaldas (1982), con una temática más calmada ${ }^{76}$.Por otra parte, en 2013 el artista Pepe Duarte deposita en el museo un lienzo de 1981, donde se puede contemplar a dos mujeres semidesnudas situadas en una arquitectura aislada, todo realizado mediante colores planos y vibrantes. Este depósito fue aceptado por la Junta de Andalucía en el 2014.

Junto a estas donaciones, Rafael Botí Torres aporta al museo un conjunto de obras pertenecientes a la colección de su padre, entre ellas el dibujo La Dama de la guitarra (Fig.40) (1951) de un miembro del Equipo 57, Agustín Ibarrola (Vizcaya, 1930). Dos grabados de Daniel Vázquez Díaz (1882-1969), realizados en 1929, que representan dos vistas de Huelva, siendo la primera del Monasterio de la Rábida -donde el propio pintor realizó unos frescos en el interior, "Poema del Descubrimiento", en 1929-, y la segunda una vista de Palos de Moguer (Fig.41), imagen a la que el artista también recurre en los mencionados frescos ${ }^{77}$. Además, Botí Torres dona un dibujo de José Caballero (1916) titulado La Hilandera (1951) (Fig.42), del que ya se conservaban dos aguafuertes en el museo y un lienzo de Antonio Merlo. Asimismo, se donan tres obras de Rafael Botí Gaitán (1990-1995), personaje representativo del panorama artístico de la ciudad de Córdoba, cuyas obras son principalmente figurativas, pero que trabajará también con la abstracción y la experimentación. De su primera etapa es el lienzo de Amalia, la gitana (1917), iconografía típica de la localidad y en íntima relación con Julio Romero de Torres; le sigue la obra Abstracto cordobés (1960), vista ejecutada a través de grandes planos geométricos de color y el lienzo de Córdoba callada o Arquitectura moderna (1986), donde la arquitectura de la calle El Bailío de la ciudad de Córdoba se torna deformada $^{78}$.

Respecto a la colección de fotografía, cabe destacar dos fotografías pertenecientes a Ladislao Rodríguez Galán (1947), Camino de ronda bajo de Medina Azabara (1995) y Salón rico de Medina Azabara (1995), las cuales fueron depositadas en el museo en el 2012 por Juan Manuel

\footnotetext{
76AA.VV, 2013: 128

77 LAFUENTE FERRARI, 2011: 44-45.

${ }^{78}$ Estas donaciones de Rafael Botí fueron aceptadas por la Junta de Andalucía en el 2015.
} 
Villanueva, y en el 2015 fue aceptadas la donación de las mismas por parte de la Junta de Andalucía ${ }^{79}$.

En cuanto a la escultura, sobresale la donación de Francisco Ariza (1937) de Aros Cósmicos (2016) (Fig.44), pieza de realizada en acero inoxidable ${ }^{80}$. Esta escultura se ingresa en el museo en calidad de producción propia. Asimismo, en el 2017 el artista cordobés realiza una instalación en el patio del Museo de Bellas Artes de Córdoba, fue "Libélula de Mayo", una libélula de acero situada en la fuente, y acompañada con varias esculturas, en la misma línea estética de sus "aros cósmicos", repartidos por todo el espacio ${ }^{81}$.

$\mathrm{Al}$ igual que la anterior, es interesante remarcar la incorporación a los fondos de la obra KAMI (2013) de Hisae Yanase Shudo (1943), producción propia realizada para el museo con motivo de la exposición "Bijin. El japonismo de Julio Romero de Torres". Hisae Yanase comienza su carrera en Córdoba en 1968, donde trabaja la cerámica como exponente de su obra, material tradicional de Japón y también de Córdoba con la cerámica califal. La unión de la modernidad con lo tradicional da lugar a unas instalaciones cargadas de poética y filosofía oriental, como es el caso de la escultura KAMI (Fig.45), instalación realizada en metal, hilo, esparto, papel y poliestireno, en la que la artista japonesa se inspira para realizarla en el lienzo Viva el pelo (1928) de Julio Romero de Torres ${ }^{82}$.

Respecto a los depósitos, en el 2013 la hija del escultor Aurelio Teno (1923-2012) incorpora al museo dos esculturas en bronce de su padre, tras la muerte de éste, como homenaje a su carrera. Teno, artista interdisciplinar, se dedica a la pintura y la escultura, además de hacerse un nombre dentro de la creación de monumentos. Su obra reconocida por su aspecto informalista, busca la expresión a través de la enfatización de las formas. El depósito consta de la escultura El triunfo de la sinrazón (1980), perteneciente a su colección sobre El Quijote, iconografía recurrente dentro de su obra, sobre la que se realiza en 2014 una muestra titulada "Teno y el Quijote". También se incorpora la escultura El Acecho (1985), un águila en posición de acechar a su presa, que actualmente se puede contemplar en el patio. Por otra parte, en 2015 se deposita la obra 536 (2006) de Pepe Morales (1933), tras la exposición antológica celebrada ese mismo año. Hasta entonces esta institución no poseía ninguna obra de esta figura del arte contemporáneo cordobés, que desde los 90 nombra sus obras con números, como una forma de crítica social. La última pieza que, hasta el momento, ha recibido el museo es la escultura de Juan Zafra (1951) titulada Artemisa despojada del chándal (2016) (Fig. 11). Con motivo de esta incorporación, en 2017 se ha organizado una muestra de la obra junto con los bocetos y maquetas preparatorias ${ }^{83}$.

\section{CONCLUSIÓN}

A lo largo de este trabajo hemos estudiado la apertura hacia la contemporaneidad del Museo de Bellas Artes de Córdoba iniciada a principios del siglo XX y su evolución hasta llegar a nuestros días, atendiendo al incremento con obras contemporáneas de los fondos que conforman su colección y al cómo esta institución se ha ido adaptando a las novedades museológicas y museográficas que marcan los nuevos tiempos. Para ello partimos del estudio de la Sección de Arte Moderno creada por iniciativa de Enrique Romero de Torres en 1902

\footnotetext{
79،"El Museo de Bellas Artes,Colecciones: Incrementos del PH”. En: <http://www.museosdeandalucia.es/cultura/museos/MBACO/index.jsp?redirect=S2_3_3.jsp\&ano=2015 $>$ [Fecha de acceso: 18/08/2017].

${ }^{80}$ Colecciones: acceso a fondos del Museo de Bellas Artes de Córdoba, [DOMUS] nºDJ1649E Andalucía: Consejería de Cultura de la Junta de Andalucía. bttp:/ / www.museosdeandalucia.es/fondos-museisticos [Fecha de acceso: 18/08/2017].

81 "El Museo de Bellas Artes, Difusión: Exposiciones".
En: $<$ http://www.museosdeandalucia.es/cultura/museos/MBACO/index.jsp?redirect=actividadExposicion.j sp\&tip $=3>$ [Fecha de acceso: 18/08/2017].

${ }^{82}$ Colecciones: acceso a fondos del Museo de Bellas Artes de Córdoba, [DOMUS] nºJ1580EAndalucía: Consejería de Cultura de la Junta de Andalucía. bttp:/ / www.museosdeandalucia.es/fondos-museisticos [Fecha de acceso: 15/08/2017].

83“"El Museo de Bellas Artes, Colecciones: Incrementos del PH" En: <http://www.museosdeandalucia.es/cultura/museos/MBACO/index.jsp?redirect=S2_3_3.jsp\&ano=2015> [Fecha de acceso: 18/08/2017].
} 
e inaugurada en 1904, incidiendo en las circunstancias que la propiciaron y repasando las obras que inicialmente la conformaron, para a continuación ir analizando el devenir de esa sección a lo largo de las décadas, su desarrollo y ampliación con nuevas piezas que el museo ha ido recibiendo por adquisición, donación o depósito. Pero no sólo nos hemos centrado en esta colección, sino que también hemos atendido a otras obras del siglo XX que entraron a formar parte de los fondos de la institución gracias a dos importantes donaciones, la Donación Avilés y la Donación Bea Pelayo, así como por el depósito de las obras del escultor Mateo Inurria.

Esto nos ha permitido apreciar cómo la colección es el eje definitorio de la institución museística, y cómo las obras que custodia marcarán la dirección y gestión del museo que, sin duda, debe ir adaptándose paulatinamente a las necesidades y peticiones de la sociedad, incidiendo en su beneficio. En este sentido, hemos analizado las transformaciones del Museo de Bellas Artes y la evolución de su gestión durante más de una centuria, comenzando por la labor desarrollada por Enrique Romero de Torres y su intento de abrir el museo a la contemporaneidad con la incorporación a sus fondos de piezas de importantes artistas coetáneos, según un particular criterio que atendía fundamentalmente a su gusto personal. Tras él, el museo vivió una etapa de estancamiento, adquiriendo nuevo impulso a partir de 1981 con el nombramiento como directora de la institución de Fuensanta García de la Torre, quien adecuó la gestión de la institución hacía unos criterios didácticos con la implantación de talleres y actividades para el público, al tiempo que solventó los problemas que tenía el antiguo Hospital de la Caridad, principalmente la falta de espacio, a partir de la realización de proyectos museográficos. Además, en cuanto al incremento de los fondos, marcó un criteriológico, enriqueciendo la colección del museo con piezas que estuviesen relacionadas o fuesen significativas dentro del ámbito cordobés. Finalmente, nos ocupamos del estado del museo en la actualidad, dirigido por José María Palencia desde 2013, dando a conocer las nuevas incorporaciones a los fondos de la institución mediante donaciones y depósitos, así como los talleres, actividades y exposiciones que se han realizado en los últimos años.

A través de este estudio, se hace evidente que, a pesar de toda la labor desarrollada en el Museo de Bellas Artes de Córdoba, la falta de espacio ha sido y sigue siendo una dificultad permanente, lo que ha determinado que el museo sólo pueda exponer una mínima parte de sus fondos de arte contemporáneo. Por otra parte, cabe señalar que desde los años 60 en Córdoba han existido instituciones, organismos y centros dedicados a las nuevas manifestaciones artísticas, pero muchas de ellas han ido desapareciendo paulatinamente, quedando presentes hoy en día la Sala VIMCORSA y su Centro de Arte Pepe Espaliú, la Fundación Provincial de Artes Plásticas Rafael Botí y las Galerías del Cardenal Salazar. Asimismo, la creación en el 2016 del Centro de la Creación Contemporánea de Córdoba (C3A), concebido para la producción, experimentación y exhibición de arte. Sin embargo, todos estos espacios, al no poseer una colección estable, no representan una vía satisfactoria para la exhibición de arte del siglo XX y del arte actual en Córdoba.

Aún queda un largo camino por recorrer en relación a la exhibición y difusión del arte contemporáneo en Córdoba. Con todo, el análisis realizado sobre el Museo de Bellas Artes nos ha permitido obtener una visión de la riqueza de los fondos de arte contemporáneo que conforman la colección del museo, así como de su trasformación y modernización en su gestión y administración, con el fin de contribuir a conservar y difundir el patrimonio cordobés, poniéndolo al servicio de la sociedad. 


\section{Bibliografía}

AA.VV.: Como administrar un museo: Manual Práctico, UNESCO e ICOM, 2006.

AA.VV.: La obra de Ricardo Baroja del Museo de Bellas Artes de Córdoba, [Catálogo de exposición] Delegación Provincial de la Consejería de Cultura de la Junta de Andalucía y Museo de Bellas Artes de Córdoba, 1990.

AA.VV.: La restauración de la fachada del Antiguo Hospital de la Caridad. Museo de Bellas Artes de Córdoba, Ministerio de Cultura y Junta de Andalucía, 2011.

AA.VV.: Museo de Bellas Artes de Córdoba, incremento de las colecciones, 1986-2006. Fuensanta García de la Torre (coord.), Consejería de Cultura, Junta de Andalucía, Museo de Bellas Artes, Sevilla, 2007.

AA.VV: 60 años de arte contemporáneo en Córdoba (1953-2013) [Catálogo de Exposición], Diputación Provincial de Córdoba, Córdoba, 2013.

AA.VV:"Homenaje a Rita Rutkowski, Hisae Yanase y Juana Castro", Catálogo de Exposición celebrada en la Sala Galatea de Córdoba, Ayuntamiento de Córdoba, Delegación de Cultura, 2013.

Aguayo Marmolejo, M.: "Origen y construcción del Hospital de la Caridad de Nuestro Señor Jesucristo", en AA.VV.: La restauración de la fachada del Antiguo Hospital de la Caridad. Museo de Bellas Artes de Córdoba, Ministerio de Cultura y Junta de Andalucía, 2011.

Alonso Fernández, L.: Museología: Introducción a la teoría y práctica del museo, Ed. Istmo S.A., Madrid, 1993.

Alquézar-Yañez, E.M.: "Los programas de colecciones del Plan Museológico", Actas de la I Jornadas de Formación Museológica, Museos y planificación: Estrategias de futuro, Ministerio de Cultura, 2008, pp. 81-90.

García De La Torre, F.: “A media luz. La sala de dibujos y grabados del Museo de Bellas Artes de Córdoba", Mus-A 0, 2002, pp. 32-37.

GARCÍA DE LA TORRE, F.: "El museo de Bellas Artes de Córdoba. Sus funciones a lo largo de 150 años", Alminar, no 33, Córdoba, 1995, pp.28-32.

García De La Torre, F.: "Incremento de las colecciones del Museo de Bellas Artes de Córdoba: reflexiones y propuestas", Mus- $A$, I, no 2, julio 2003, pp. 41- 50.

García De La Torre, F.: "Pasado, presente y futuro de una colección. Los dibujos del Museo de Bellas Artes de Córdoba", catálogo de la exposición Ars Delineandi o el arte de dibujar. Una aproximación a las colecciones de dibujo de los museos andaluces, Museo de Bellas Artes de Granada, mayo-agosto de 2009, Granada, 2009, pp. 61-73.

García De La Torre, F.: Dibujos del Museo de Bellas Artes de Córdoba. Adquisiciones y donaciones, Catálogo de la exposición, Fundación José Manuel Lara, Sevilla, 1992-2003

García De La Torre, Fuensanta, "Inventarios de una colección. Los dibujos del Museo de Bellas Artes de Córdoba", Pulchrum, Scripta varia in honorem $M^{a}$ Concepción García Gainza, Universidad de Navarra, Pamplona, 2011, pp. 341-347

Hernández Hernández, F.: Manual de museología, Ed. Síntesis, Madrid, 1994.

Hochroth, L. (ed.)/ICOM: Código de deontología del ICOM para los museos, Consejo Internacional de Museos, París, 2006.

Jiménez, L. (coord.): Coleccionismo artístico: del retrato burgués a la obra de Adolfo Lozano Sidro (18721935). Ilustrador de Blanco y Negro, Ámbito Cultural de El Corte Inglés de Málaga, [Catálogo de la exposición celebrada en Málaga de 17 de Enero al 7 de Marzo de 2014], 2014.

Lafuente Ferrari, E.: Recuerdo de Daniel Várquez Díaz en su centenario, Biblioteca Virtual Miguel de Cervantes, Alicante, 2011.

López Rodríguez, J.R.: Historia de los Museos de Andalucía, Universidad de Sevilla, Sevilla, 2010.

Martín Fernández, E.: "Un pintor para los primeros años del siglo XX: la figura singular de Francisco Iturrino", Ondaren ${ }^{\circ} 23,2004$, pp. 575-590.

Martín Martín, F.: "Museos y adquisiciones", Laboratorio de Arte: Revista del Departamento de Historia del Arte, no 3, 1990, pp. 259-264.

MARTÍN MARTIN, F.:"Reflexiones en torno al museo en la actualidad", Laboratorio de Arte no7, 1994, pp. 263-282. 
Martinez Lombó, E.: “Arte ¿para todos? La creación de los museos provinciales en el siglo XIX: ideologías, intereses y logros.", Congreso Internacional Imagen Apariencia, Universidad de Murcia, (2009).

Montes Ruiz, R.: Mateo Inurria en el Museo de Bellas Artes de Córdoba. CajaSur Publicaciones, Córdoba, 1996.

Mudarra Barrero, M. "Incrementando las colecciones de los museos andaluces", Mus- $A$ n ${ }^{\circ}$, Julio 2003, pp. 16-35.

Palencia Cerezo, J.M.: "El Museo de Bellas Artes de Córdoba, su historia y colecciones", Alminar, n'33, Córdoba, abril de 1995, pp. 16-20.

Palencia Cerezo, J.M.: "Fuensanta García de la Torre. Directora del Museo de Bellas Artes de Córdoba (1981-2012)" en DE CAVI, S. (Ed. Lit.) Dibujo y ornamento: trazas y dibujos de artes decorativas entre Portugal, España, Italia, Malta y Grecia. Estudios en honor de Fuensanta García de la Torre. Diputación provincial de Córdoba y De Luca EditoriD’Arte, Córdoba, 2015.

Palencia Cerezo, J.M.: Museo de Bellas Artes de Córdoba, guía oficial, Junta de Andalucía, Consejería de Cultura, 2003.

Palencia Cerezo, J.M: Enrique Romero de Torres. Junta de Andalucía, Consejería de Cultura, Sevilla, 2006.

Peñuelas I Reixach, $\mathrm{Ll}$ (ed.): Administración y dirección de los museos: aspectos jurídicos, Fundació Gala-Salvador Dalí, Marcial Pons, Madrid, 2008.

Pérez Villén, A.L.: "Juego de paradojas. Análisis de la pintura como hermenéutica" Catálogo de la Exposición "Looking Back" celebrada en el Palacio de la Merced en octubre de 1998, Diputación de Córdoba, Delegación de Cultura, 1998.

Rico, J.C.: Manual práctico de museologia, museografía y técnicas expositivas, Ed. Silex, Madrid, 2006.

Rico, J.C.: Montaje de Exposiciones: Museos, Arquitectura y Arte, Ed. Silex, Madrid, 2007.

Santacana Maestre, J y Serrat Antolí, N. (coord.): Museografía didáctica, Ed. Ariel., Barcelona, 2005.

Santacana Mestre, J. y Hernández Cardona, F.X.: Museología crítica, Ed. Trea S.L., Asturias, 2006.

Santiago Paéz, E.M.: "Fuensanta García de la Torre. Entre dos pasiones el museo y el dibujo", en DE CAVI, S. (Ed. Lit.) Dibujo y omamento: trazas y dibujos de artes decorativas entre Portugal, España, Italia, Malta y Grecia, Diputación provincial de Córdoba, 2015.

Soto Cano, M.: "Los primeros años del escultor Quintín de Torre (1877-1910)", Sancho el Sabio, 32, 2010.

Zueras Torrens, F. (coord.), Adolfo Lozano Sidro (1872-1935), Priego de Córdoba, Ayuntamiento de Priego de Córdoba y la Diputación Provincial de Córdoba [Catálogo de la exposición celebrada en Priego de Córdoba, Diciembre, 2000], 2000. 